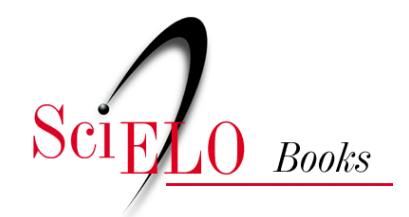

EdUfSCar

\title{
4 - Desenvolvimento de nanodispositivos baseados em biomoléculas: abordagens computacionais
}

\author{
Eduardo de Faria Franca \\ Guedmiller Souza de Oliveira \\ Jéssica Cristiane Magalhães Ierich \\ Ana Carolina Araújo Vig \\ Caroline P. Brandini \\ Ariana de Souza Moraes \\ Fábio de Lima Leite
}

\section{SciELO Books / SciELO Livros / SciELO Libros}

FRANCA, E.F., OLIVEIRA, G.S., IERICH, J.C.M., VIG, A.C.A., BRANDINI, C.P., MORAES, A.S., and LEITE, F.L. Desenvolvimento de nanodispositivos baseados em biomoléculas: abordagens computacionais. In: FREITAS, L.C.G., and OLIVEIRA, G.S., orgs. Aplicações de química teórica no estudo de materiais: métodos in silico para nanomateriais [online]. São Carlos: EdUFSCar, 2018, pp. 118-155. ISBN 978-65-80216-12-3. Avalaible from: doi: $10.7476 / 9786580216123.0005$. Also available in ePUB from: http://books.scielo.org/id/nvnjd/epub/freitas-9786580216123.epub.

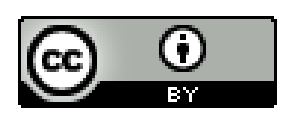

All the contents of this work, except where otherwise noted, is licensed under a Creative Commons Attribution 4.0 International license.

Todo o conteúdo deste trabalho, exceto quando houver ressalva, é publicado sob a licença Creative Commons Atribição 4.0. 


\section{DESENVOLVIMENTO DE NANODISPOSITIVOS BASEADOS EM BIOMOLÉCULAS}

abordagens computacionais

Eduardo de Faria Franca ${ }^{1}$

GuedMiller Souza de Oliveria,

Jéssica Cristiane Magalhães Ierich, Ana Carolina Araúujo Vig, Caroline P. Brandin, Ariana de Souza Moraes e Fábio de Lima Lette ${ }^{2}$

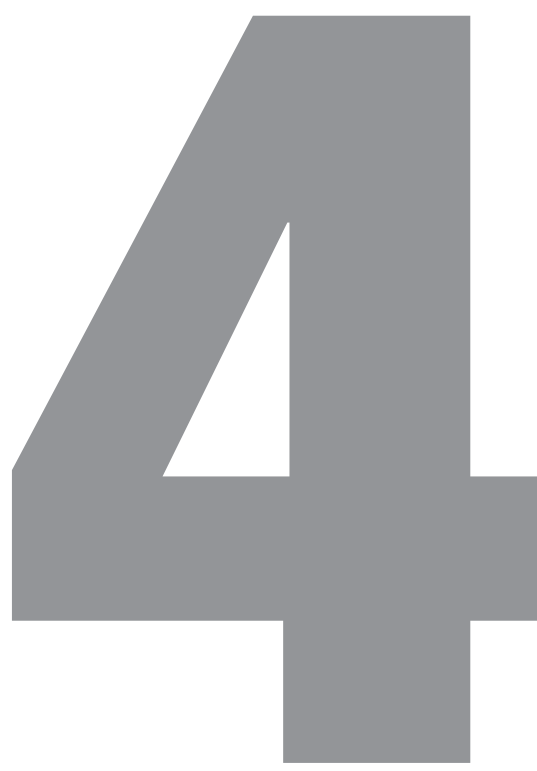

\footnotetext{
1 Instituto de Química da Universidade Federal de Uberlândia (UFU). E-mail: <eduardofranca@ufu.br>.

2 Todos os demais autores são membros do Grupo de Nanoneurobiofísica do Departamento de Física, Química e Matemática da Universidade Federal de São Carlos, campus Sorocaba-SP. E-mail: <fabioleite@ufscar.com>.
} 


\subsection{INTRODUÇÃ $0^{3}$}

A investigação de processos em escala atomística envolve a aplicação de ferramentas sofisticadas e que requerem altos investimentos. Atualmente, técnicas experimentais como a Microscopia de Força Atômica e a Microscopia Eletrônica oferecem uma boa aproximação na caracterização de processos em nível molecular. No entanto, apesar de as medidas e imagens obtidas serem muito informativas, muitas vezes o detalhamento do comportamento no tempo do sistema em estudo é dificultado, dada a escala nanométrica. Dessa forma, a Modelagem Molecular Computacional (MMC) surge como alternativa de complementação e interpretação dos resultados experimentais. A MMC se resume a um conjunto de metodologias e aproximações computacionais capazes de gerar um modelo descritivo de determinado sistema, o qual possibilita a reprodução computacional de suas propriedades reais. Nesse contexto, são inúmeras as aplicações da MMC no estudo de processos bioquímicos envolvidos no funcionamento de biomoléculas.

Em especial, é crescente o uso de nanobiotecnologias para fins de monitoramento ambiental e, por conseguinte, para a elucidação e o diagnóstico de doenças complexas, como as doenças neurodegenerativas. Inclusos nessa modalidade estão os nanobiossensores. Tais sensores específicos utilizam pontas do Microscópio de Força Atômica (AFM, do inglês Atomic Force Microscope) para a identificação precisa de determinados analitos, como, por exemplo, herbicidas inibidores enzimáticos. A aplicação da MMC no estudo de modificações químicas das pontas de AFM, durante o desenvolvimento de nanobiossensores, tem fornecido dados importantes sobre o recobrimento de superfícies por biomoléculas específicas. Um modelo capaz de descrever as propriedades de recobrimento das pontas, por exemplo, pode fornecer um direcionamento aos estudos experimentais, identificando sítios reacio-

3 Os autores agradecem a agência de fomento FAPESP sob os seguintes números de auxílio: 13/09746-5; 13/21958-8; 14/26369-3; 15/05283-6; 14/12082-4 e 13/04320-0. E também ao CNPq, processo 459768/2014-0. 
nais disponíveis para a interação com o analito que se pretende detectar. Com essa identificação, pode-se, assim, determinar o protocolo mais adequado para imobilização das biomoléculas no nanossensor biológico.

Tendo em vista o supracitado, o presente capítulo tem por objetivo elucidar os princípios que cingem a aplicação da MMC no estudo e desenvolvimento de nanobiossensores, apresentando as técnicas computacionais úteis na descrição da funcionalização de pontas de AFM e o panorama atual das pesquisas na área.

\subsection{NANOBIOSSENSORES E APLICABILIDADE}

A utilização do AFM como ferramenta de sensoriamento requisitou da comunidade científica meios para o detalhamento, em escala molecular, dos processos que descrevem a construção e aplicação desses nanodispositivos. Para o entendimento desses processos, faz-se necessária a descrição do modo de funcionamento do microscópio em questão, bem como do fundamento que rege o sensoriamento mediado pelos nanobiossensores de pontas de AFM, nos itens a seguir, para posterior elucidação dos protocolos de detalhamento molecular a partir de métodos computacionais.

\subsubsection{Microscopia de tunelamento}

A possibilidade de investigação de processos em escala nanométrica (da ordem de $10^{-9}$ ) surgiu a partir da necessidade de maior compreensão quanto ao comportamento e às propriedades elétricas de finas camadas de óxidos sobre os quais ${ }^{4}$ se questionava no final da década de 1970 . Sem um instrumento que pudesse gerar respostas para seus questionamentos, desenvolveram o microscópio de tunelamento (STM, do inglês Scanning Tunnelling Microscope), que funciona, como apresentado na Figura 4.1, a partir da varredura de uma amostra por uma ponta fina de tungstênio fixada a um piezoelétrico $\left(P_{\mathrm{x}}, P_{\mathrm{y}}\right.$ e $\left.P_{\mathrm{z}}\right)$, em velocidade e distância da amostra $(s)$ constantes; uma voltagem $\left(V_{\mathrm{z}}\right)$ é aplicada na ponta e na amostra $\left(V_{\mathrm{t}}\right)$ pelo piezo $\left(P_{\mathrm{z}}\right)$, intermediada por uma unidade controladora $(U C)$ que retorna uma imagem topográfica $(A$ e $B)$ da superfície da amostra $(C)$, pela corrente de tunelamento gerada, como um efeito da mecânica quântica. ${ }^{5}$ 


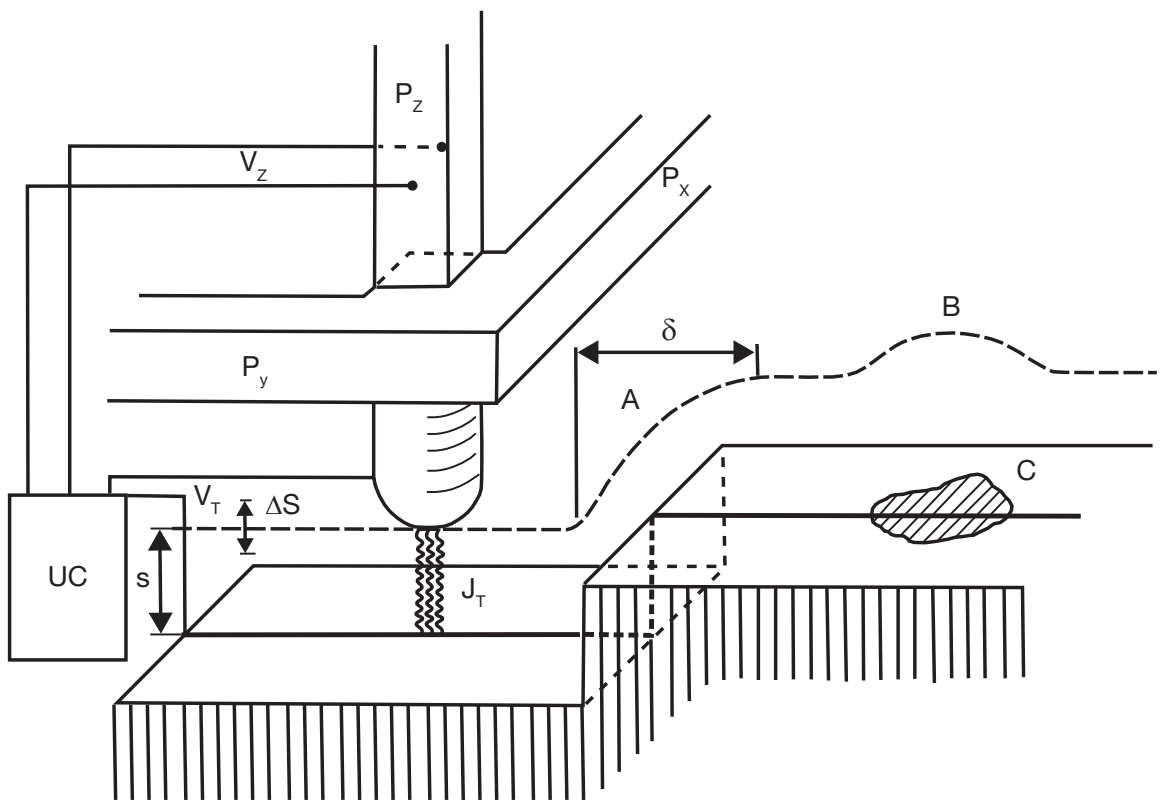

Figura 4.1 Princípio do funcionamento de um microscópio de tunelamento (STM).

Fonte: Binnig e Rohrer. ${ }^{6}$

A microscopia de tunelamento possibilitou, além da caracterização da amostra através de imagens topográficas, a modificação de superfícies como o posicionamento de átomos simples de xenônio sobre uma superfície de níquel, realizado no estudo de Eigler e Schweiser, ${ }^{7}$ pesquisadores da IBM (do inglês International Business Machines). Os cientistas moveram átomo por átomo na superfície e os organizaram com precisão atômica, como apresentado na Figura 4.2. Vislumbraram, com seus estudos, a fabricação de estruturas sobrepostas e análises de suas propriedades. $^{8}$ 

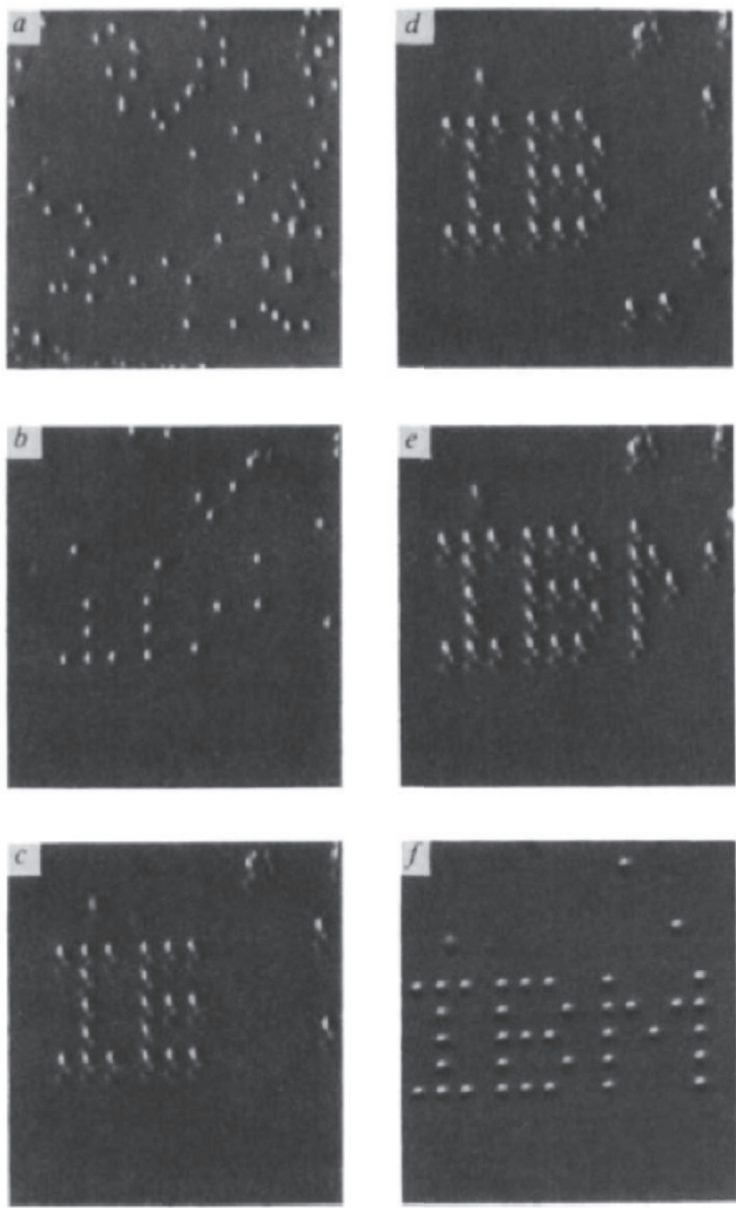

Figura 4.2 Sequência de imagens de STM mostrando o posicionamento de átomos de xenônio em uma superfície de níquel, este feito também pelo STM.

Fonte: Eigler e Schweizer. ${ }^{9}$

Atualmente, o STM tem sido utilizado para estudos de superfícies com precisões nanométricas. ${ }^{10}$

\subsubsection{Microscopia de força atômica}

Após o desenvolvimento do STM, outra ferramenta que permite estudos em escala nanométrica é o AFM, bastante semelhante ao STM, embora com algumas

9 Id. ibid.

10 Sutter et al. (2009), Tapasztó et al. (2008). 
diferenças, como a utilização de forças atômicas (Van der Waals, por exemplo) em vez de corrente de tunelamento, além de ser uma opção para análise de amostras biológicas, uma vez que pode ser feita em ar ou em meio líquido, propiciando a viabilidade das amostras. ${ }^{11}$

O princípio de funcionamento do AFM tem como base a transformação do sinal de deflexão do cantilever em imagem ou medida de força (Van der Waals, eletrostática, capilaridade, magnética, repulsão iônica e fricção). Conforme pode ser observado na Figura 4.3, um laser é incidido sobre o cantilever, que deflete, em razão da dinâmica de interação entre a ponta e a amostra. O laser é, então, refletido para um fotodetector, que recebe o sinal da oscilação do cantilever e o envia a um controlador, transformando o sinal em imagem ou medida de força no computador. A oscilação da amostra é ocasionada pelo piezoelétrico, que se movimenta nos eixos $x, y$ e $z .^{12}$

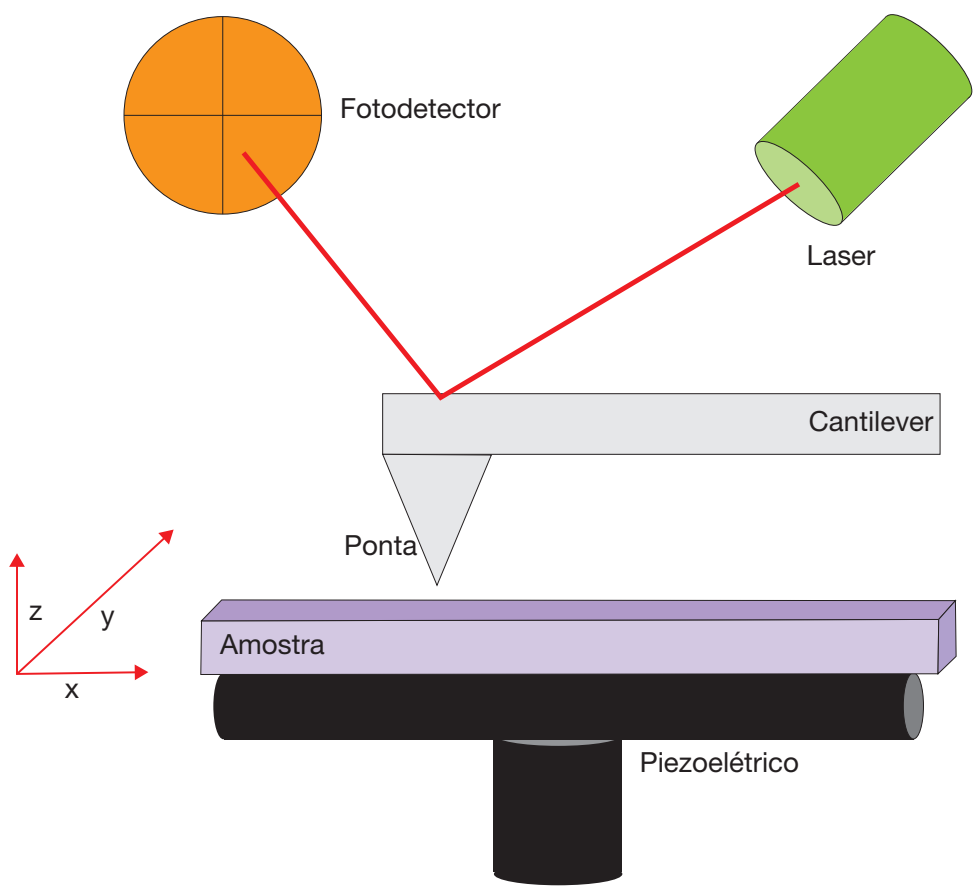

Figura 4.3 Princípio de funcionamento do AFM.

A utilização de amostras biológicas e biomoléculas para estudos morfológicos e de interações, com AFM, vem se desenvolvendo principalmente no que se refere ao estudo de interações entre enzimas ou anticorpos e seus ligantes; estudos de monitoramento ambiental com interações enzima-herbicida obtiveram resultados promissores para a aplicação do AFM também nessa área, com a imobilização

11 Binnig et al. (1986), Tamayo et al. (2001), García e Pérez (2002), Hermans (2012).

12 Meyer (1992) 
de biomoléculas em nanossuperfícies, como no cantilever do AFM e em outras superfícies. $^{13}$

\subsubsection{Desenvolvimento de nanobiossensores: imobilização de biomoléculas em nanossuperfícies}

Para estudos de interação enzima-herbicida, faz-se a imobilização das biomoléculas e seus ligantes em superfícies (superfície de deposição da amostra, por exemplo) a partir de interações químicas covalentes, como proposto pioneiramente por Butt et al. ${ }^{14}$ e também por Lyubchenko et al. ${ }^{15}$ Uma superfície de mica muscovita facilmente clivável e negativamente carregada pode ser silanizada com aminopropiltrietoxisilano (APTES), formando uma camada de funcionalização que apresenta grupos amina $\left(\mathrm{NH}_{2}\right)$ disponíveis para interação covalente com um cross-linker, podendo ser, por exemplo, o glutaraldeído, que possui grupos carboxila (-COOH), para assim interagir com biomoléculas ou seus ligantes, conforme seus grupos funcionais disponíveis para interação (Figura 4.4(a)).

O mesmo pode ser realizado com nanossuperfícies, como a ponta do AFM, geralmente fabricada de nitreto ou nitreto de silício. ${ }^{16} \mathrm{~A}$ silanização da ponta de AFM com APTES forma uma camada de recobrimento que apresenta grupos amina disponíveis para a interação com os grupos carboxila do glutaraldeído, que, por sua vez, disponibiliza terminações para interação covalente com as biomoléculas (enzimas), sendo possível sua imobilização nas pontas de AFM, resultando no desenvolvimento de um nanobiossensor, como demonstrado pela Figura 4.4(b).

\subsubsection{Técnicas computacionais aplicadas ao estudo e à representação de compostos imobilizados}

O estudo de sistemas biológicos complexos, como proteínas, enzimas e anticorpos, engloba a descrição e o entendimento dos fenômenos e mecanismos envolvidos em sua atuação. No entanto, em escala atômica, essa tarefa se torna difícil não apenas pela elevada complexidade característica dessas macromoléculas, mas também pelo fato de a ciência ainda não compreender e/ou descrever vários pontos do funcionamento global de tais sistemas. ${ }^{17}$ É nesse contexto que as técnicas de MMC tiveram seu desenvolvimento estimulado. ${ }^{18}$

3 Da Silva et al. (2013, 2014), Deda et al. (2013), Castro Bueno et al. (2014).

14 Butt et al. (1990).

15 Lyubchenko et al. (1993)

16 Etchegaray et al. (2010).

17 Wooley e Lin (2005).

18 Ramachandran et al. (2008). 


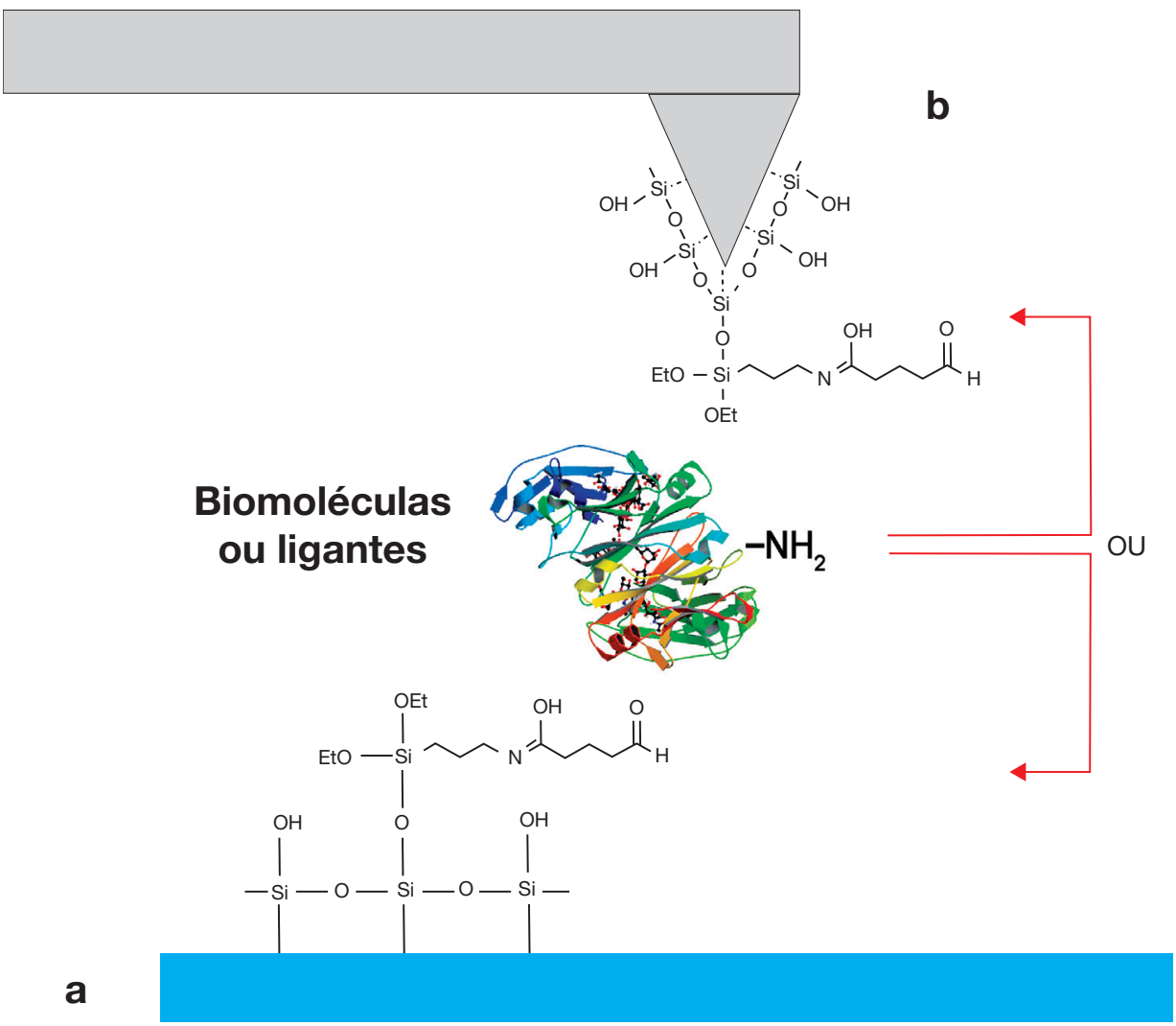

Figura 4.4 Funcionalização e imobilização de biomoléculas em superfícies ou nanossuperfícies, resultando na construção de (a) superfície de deposição da amostra ou (b) no desenvolvimento do nanobiossensor para estudo das interações enzima-ligante.

Em âmbito geral, a aplicação de ferramentas computacionais é útil para entender sobre a estrutura tridimensional e a estabilidade de macromoléculas, a caracterização do enovelamento proteico, o estudo do reconhecimento molecular e as interações intermoleculares, a descrição da catálise enzimática, entre outros conteúdos. ${ }^{19}$ Em especial, resultados promissores têm sido obtidos aplicando a MMC como ferramenta de direcionamento para o desenvolvimento de nanobiossensores de pontas de AFM. As técnicas experimentais de microscopia no estudo de materiais em escala nanométrica, conforme discutido nos itens anteriores, pertencem a um campo de fronteira transdisciplinar conhecido como Nanociência e Nanotecnologia. ${ }^{20} \mathrm{O}$ grande desafio reside em controlar as estruturas e propriedades em escala atômica, molecular e supramolecular e, assim, desenvolver e aplicar nanodispositivos. 
No contexto de desenvolvimento de nanobiossensores, foco deste capítulo, a modificação química das pontas, descrita no item 4.2.3, é um meio de facilitar interações moleculares específicas. Dependendo da biomolécula em estudo, podem ser definidos diferentes tipos de modificações químicas da ponta do AFM, a fim de melhor se adequar aos grupos reativos presentes ao longo da estrutura molecular. Computacionalmente, a modificação química é realizada a partir de um programa para desenho de estrutura molecular. ${ }^{21}$ Em contrapartida, as reações experimentais dependem de uma molécula ligante que estabeleça uma ponte adequada para que a interação entre a ponta metálica do AFM e a biomolécula seja viável; isto requer um estudo aprofundado das condições termodinâmicas favoráveis que se adéquem à imobilização de biomoléculas. ${ }^{22}$ Desta forma, simulações computacionais podem reduzir o tempo de procura por um reagente adequado para este fim, bem como o custo.

Em condições ambientes normais, as pontas de AFM podem sofrer oxidação, formando grupos $\mathrm{SiO}_{2}$ na superfície. Quando há oxidação parcial, $\mathrm{SiOH}$ é formado na camada mais externa da ponta. Estes grupos reagem fortemente com grupos silanos que são utilizados para funcionalização de pontas de AFM. O composto APTES é um reagente comum para este fim, pois o grupo amino em uma de suas extremidades é muito reativo e pode ser utilizado para reação com outras moléculas, como, por exemplo, o glutaraldeído, que se liga aos constituintes biomoleculares com facilidade. ${ }^{23}$

Além do glutaraldeído, outros grupos podem ser utilizados para a imobilização de biomoléculas, dependendo da estrutura específica que se deseja imobilizar. Pesquisas computacionais podem trabalhar na proposição de grupos reativos para serem utilizados nesse processo, já que a atividade computacional é mais favorável com relação ao custo-benefício, quando comparada com a rotina laboratorial. A Figura 4.5 ilustra uma simulação computacional, por Dinâmica Molecular (DM), da imobilização da enzima AcetilCoA carboxilase (ACCase), em uma superfície funcionalizada com o composto APTES, quimicamente ligado ao glutaraldeído para o desenvolvimento de um biossensor em nanoescala. ${ }^{24}$ Essas simulações são de fundamental importância para a compreensão do experimento atomisticamente, dada a dificuldade de prever, por métodos experimentais, a posição favorável em que a biomolécula será imobilizada e também as regiões de maior interação com seus substratos e/ou inibidores.

Nesse contexto, as técnicas computacionais que podem ser utilizadas para complementar os resultados experimentais são: (i) Modelagem por Homologia; (ii) Docking Molecular; (iii) DM; (iv) Mecânica Quântica e os cálculos híbridos de QM/ MM (Mecânica Quântica e Mecânica Molecular); e (v) Dinâmica Molecular Direcionada (SMD, do inglês Steered Molecular Dynamics).

21 Amarante et al. (2014), Oliveira et al. (2013).

22 Amarante et al. (2014).

23 Etchegaray et al. (2010).

24 Oliveira et al. (2013). 


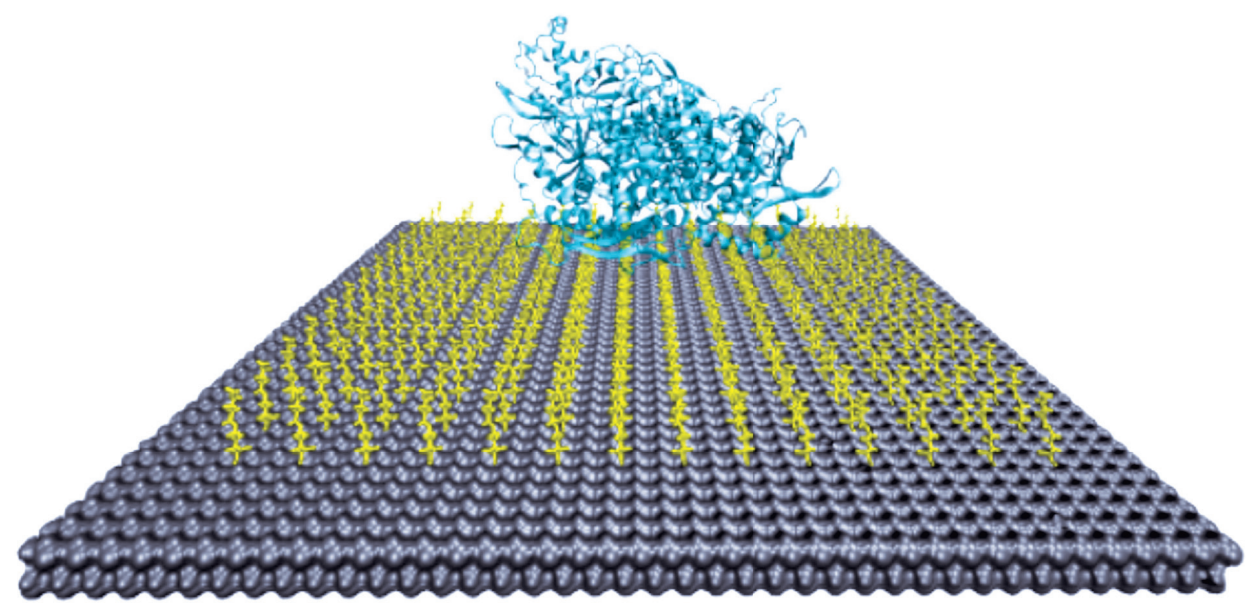

Figura 4.5 Representação esquemática de uma superfície funcionalizada com APTES + glutaraldeído (linker), com a finalidade de imobilização biomolecular. Em cinza é representada uma superfície de nitreto de silício ligada ao linker em amarelo. Em azul ciano está representada a enzima.

\subsubsection{Modelagem por homologia}

As biomoléculas são descritas por estruturas altamente específicas e complexas, as quais podem possuir vários níveis de organização estrutural. ${ }^{25}$ Dessa forma, sua descrição engloba a aplicação de técnicas experimentais refinadas de estudo e descrição estrutural, em especial a Difração de Raios-X (DRX), técnicas essas que funcionam como fontes primárias de dados estruturais. ${ }^{26}$ Em DRX, os cristais da biomolécula são irradiados por um feixe de raios- $\mathrm{X}$, de forma que os eventos de interferência gerem um padrão de difração crucial para a descrição da estrutura tridimensional. ${ }^{27}$ A determinação da primeira estrutura tridimensional de proteína ocorreu na década de 1950, quando Kendrew et al. ${ }^{28}$ descreveram por DRX a mioglobina. A partir daí, várias outras proteínas foram sendo investigadas e determinadas. Com o avanço tecnológico nas últimas décadas, marcado pela inserção de novos componentes de software e hardware, as técnicas experimentais de determinação estrutural foram aprimoradas, de forma a gerar um notável crescimento no número de proteínas com estrutura tridimensional, descritas com base no maior repositório de estruturas tridimensionais, o Protein Data Bank (PDB), ${ }^{29}$ que conta com mais de 139.000 estruturas

\footnotetext{
Kessel e Ben-Tal (2011), Nelson e Cox (2008), Voet e Voet (2011).

Rhodes (2006).

Giorgetti et al. (2005).

Kendrew et al. (1958).

29 Berman et al. (2000).
} 
depositadas atualmente. As informações disponíveis nesse banco de dados advêm das coordenadas atômicas obtidas pela comunidade científica.

No entanto, algumas dificuldades na aplicação de tais técnicas podem comprometer a determinação estrutural, impedindo a descrição de algumas macromoléculas, ou mesmo gerando uma descrição que pode ser aprimorada, dadas algumas incertezas com relação à identidade e à posição de átomos derivados de dados de densidade eletrônica. ${ }^{30}$ Tais incertezas no modelo atômico podem ter consequências significativas em estudos subsequentes, principalmente aqueles envolvendo docking e DM. ${ }^{31}$ Assim, a MMC surge como alternativa na solução de vários problemas básicos recorrentes na aplicação de métodos experimentais, assumindo um papel complementar às técnicas experimentais na obtenção e no refinamento de modelos tridimensionais de biomoléculas. ${ }^{32}$

Algumas proteínas compartilham graus de similaridade significativos da sequência de aminoácidos e da estrutura tridimensional e, por isso, são denominadas proteínas homólogas. ${ }^{33}$ Geralmente, proteínas que realizam funções similares em organismos diferentes compartilham certo grau de identidade. ${ }^{34}$ De acordo com a teoria evolutiva, espécies relacionadas evoluíram de um ancestral comum, o que sugere que cada proteína, da mesma forma, deve ter evoluído a partir de uma correspondente do mesmo ancestral. ${ }^{35}$ Dessa forma, proteínas de uma mesma família evolutiva compartilham várias similaridades, no que se fundamenta a técnica de modelagem por homologia estrutural. ${ }^{36}$

De forma geral, a modelagem por homologia aplica ferramentas computacionais de forma a predizer a estrutura tridimensional de uma proteína-alvo a partir de estruturas homólogas conhecidas no PDB. ${ }^{37}$ A aplicação de tal técnica envolve as seguintes etapas: (i) identificação e seleção das proteínas que servirão como molde; (ii) alinhamento das sequências de resíduos da proteína-alvo com os moldes; (iii) construção das coordenadas do modelo; e (iv) validação e otimização do modelo (Figura 4.6). ${ }^{38}$

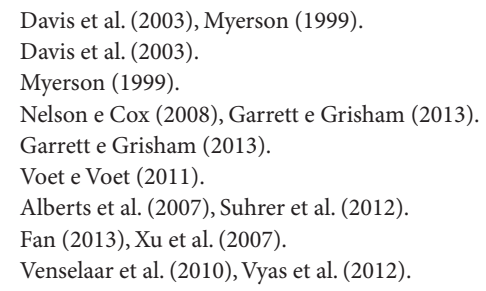




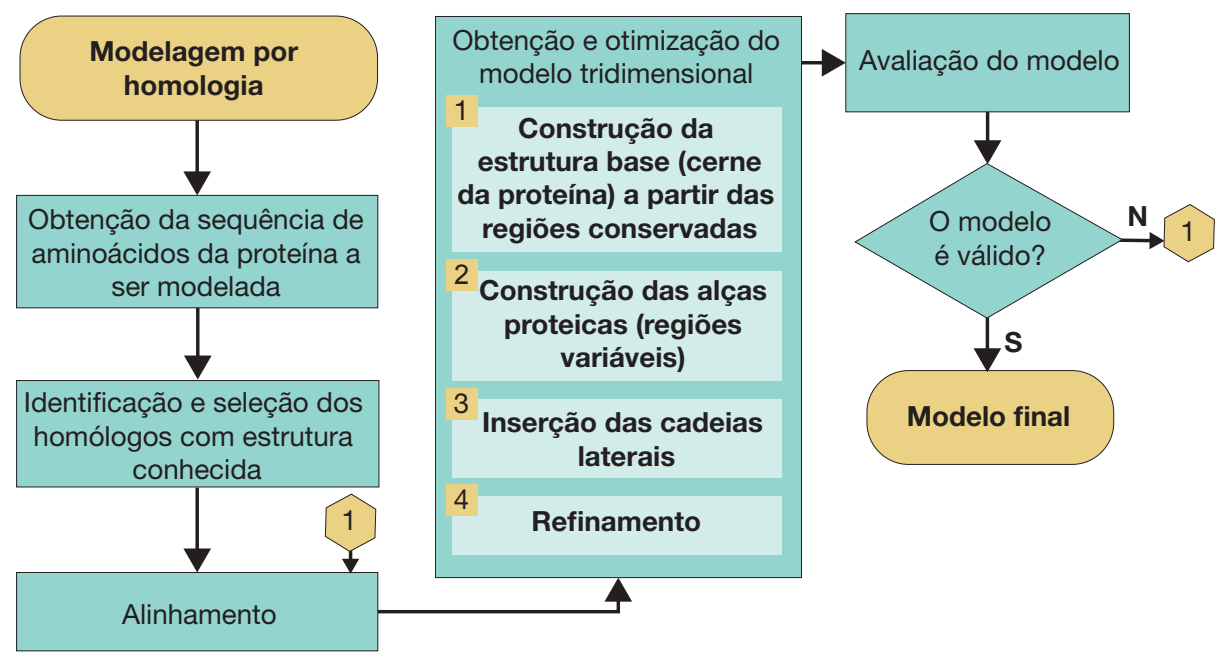

Figura 4.6 Fluxograma de aplicação da modelagem por homologia.

Previamente à aplicação da técnica de modelagem comparativa propriamente dita, o usuário deve obter os dados sobre a estrutura primária da proteína/enzima a ser modelada, ou seja, sua sequência de aminoácidos, a qual servirá de guia para os passos subsequentes. A sequência de aminoácidos pode ser obtida em bancos de dados específicos, como o Protein-NCBI, ${ }^{39}$ que disponibiliza sequências proteicas e é mantido pelo National Center for Biotechnology Information (NCBI), e o UniProt Knowledgebase (UniProtKB), ${ }^{40}$ que fornece informações sobre sequência, função e propriedades de proteínas.

A sequência de aminoácidos da proteína-alvo é essencial para a primeira etapa da aplicação da modelagem por homologia: identificação e seleção dos moldes a serem utilizados para construção do modelo. Os moldes são encontrados por similaridade com a sequência-alvo ou também por demais critérios, como informação estrutural. ${ }^{41}$ A existência de estruturas homólogas no repositório PDB é a principal condição para a realização da modelagem comparativa. ${ }^{42}$ Alguns algoritmos específicos auxiliam na identificação dos moldes, buscando por similaridades entre a sequência de aminoácidos da proteína-alvo e as sequências disponíveis em bancos de dados e calculando a significância estatística das similaridades. ${ }^{43}$ É o caso do software Protein Similarity Search (FASTA <www.ebi.ac.uk/Tools/sss/fasta/>) ${ }^{44}$ e do Basic Local Alignment Search Tool (BLAST <http://blast.ncbi.nlm.nih.gov/Blast.cgi>). ${ }^{45} \mathrm{Um}$ ou mais moldes podem ser designados para a modelagem. As proteínas com maior

39 Pruitt et al. (2007).

40 Magrane e Consortium (2011).

41 Contreras-Moreira et al. (2002).

42 Alberts et al. (2007), Kumar e Filipski (2007).

43 Contreras-Moreira et al. (2002).

44 Lipman e Pearson (1985), Pearson e Lipman (1988).

45 Altschul et al. (1990). 
grau de similaridade são, geralmente, as mais indicadas para servirem de molde. ${ }^{46}$ Quando a identidade entre as sequências for inferior a $30 \%$, a construção do modelo é dificultada, havendo a necessidade de aplicação de estratégias específicas. ${ }^{47}$

A etapa subsequente é o alinhamento das sequências de aminoácidos da proteína-alvo e dos moldes. No alinhamento, a similaridade entre as sequências é medida por comparação entre elas, realizada de forma a evidenciar as regiões conservadas e as regiões variáveis. ${ }^{48}$ Ao longo da evolução das proteínas, mutações podem ocorrer de forma a remover, substituir e inserir determinado aminoácido na cadeia polipeptídica. ${ }^{49}$ Essas mutações podem modificar o comprimento da sequência, sendo necessária a inserção de espaços vazios, as lacunas ou gaps, posicionados da melhor forma pelo software de alinhamento, a fim de igualar as sequências para comparação..$^{50} \mathrm{O}$ alinhamento das sequências funciona como guia para a construção do modelo, sendo uma das etapas mais críticas e intimamente relacionadas à qualidade da estrutura final. ${ }^{51}$

Após o alinhamento, é iniciada a etapa de construção do modelo da proteína-alvo. Primeiramente, a estrutura-base da proteína é construída a partir das regiões conservadas, identificadas pelo alinhamento. ${ }^{52}$ Em seguida, as regiões de dobramento, as alças ou loops que conectam elementos de estrutura secundária e apresentam elevada flexibilidade, são modeladas. ${ }^{53} \mathrm{~A}$ precisão da modelagem de tais regiões é fator determinante na utilidade dos modelos construídos em estudos das interações proteína-ligante. ${ }^{54} \mathrm{~A}$ construção das alças pode ocorrer de duas formas: (i) com base em bancos de dados estruturais internos dos programas de modelagem, com referência em estruturas disponíveis no PDB; e (ii) a partir da modelagem ab initio, que toma como base a sequência de aminoácidos da região para gerar a estrutura tridimensional. ${ }^{55}$ Por fim, são adicionadas as cadeias laterais à cadeia principal, tarefa que, em geral, é fundamentada em bancos de dados específicos advindos de estruturas cristalográficas conhecidas e bem refinadas. ${ }^{56}$

Obtido o modelo tridimensional, ele deve passar por uma etapa de refinamento, a qual visa corrigir possíveis erros e distorções na geometria que possam ter ocorrido durante o processo de modelagem, principalmente com relação às alças e cadeias laterais. ${ }^{57}$ De forma geral, o refinamento aproxima a resolução do modelo àquela apresentada por estruturas experimentais. ${ }^{58}$ Essa etapa se fundamenta na

\footnotetext{
46 Santos-Filho e Alencastro (2003).

47 Contreras-Moreira et al. (2002), Zhang (2008), Venclovas (2012), Xiang (2006).

48 Altschul (1991), Santos-Filho e Alencastro (2003).

49 Alberts et al. (2007), Kumar e Filipski (2007).

50 Venclovas (2012), Kumar e Filipski (2007), Kinch e Grishin (2002).

51 Peitsch (2002).

52 Daga et al. (2010), Schwede et al. (2003).

53 Nelson e Cox (2008), Santos-Filho e Alencastro (2003).

54 Fiser e Šali (2003).

55 Arnautova et al. (2011), Fiser e Šali (2003).

56 Daga et al. (2010), Bower et al. (1997).

57 Xiang (2006), Schwede et al. (2003).

58 Zhang (2009).
} 
minimização de energia, por meio da movimentação dos átomos, de forma a liberar energia local presa e aproximar-se da estrutura nativa da proteína. ${ }^{59} \mathrm{~A}$ minimização de energia pode ser realizada pela aplicação de ferramentas de DM, permitindo o relaxamento da estrutura global em água, além de corrigir contatos atômicos muito próximos. ${ }^{60}$ Após o refinamento estrutural, segue a etapa final da modelagem por homologia, a validação, que envolve a avaliação das características do modelo gerado. A aplicação específica de um modelo tridimensional está estritamente relacionada à sua qualidade. ${ }^{61}$ Entre os principais fatores com influência na qualidade do modelo final estão: (i) a identidade entre as sequências-alvo e molde (dependente da relação evolutiva entre as proteínas, assim como da similaridade das sequências); (ii) a escolha dos moldes e precisão no alinhamento realizado durante a modelagem; e (iii) precisão da modelagem, principalmente das regiões variáveis, como as alças. ${ }^{62}$ Em geral, os erros abrangem o empacotamento das cadeias laterais, os desvios ou as distorções de regiões centrais da cadeia principal, assim como as regiões de alças, em que os erros maiores podem ocorrer, dada a dificuldade de modelá-las. ${ }^{63}$

A validação do modelo tridimensional envolve a estimativa dos erros presentes na estrutura tridimensional, que pode ser realizada englobando duas abordagens principais: (i) cálculo da energia do modelo com base em um campo de força, cálculo este que avalia os comprimentos e ângulos de ligações químicas, assim como desacordos atômicos e impedimentos estéricos; e (ii) determinação dos índices de normalidade, envolvendo a comparação das características apresentadas pelo modelo com aquelas apresentadas por estruturas refinadas, ou seja, essa abordagem define o quão normal ou incomum é determinada característica do modelo quando comparada com estruturas experimentais conhecidas. ${ }^{64} \mathrm{~A}$ validação pode guiar algumas melhorias necessárias, as quais resultarão na obtenção do modelo tridimensional final para a proteína-alvo.

Cada uma das etapas supracitadas está fundamentada na utilização de uma série de programas, servidores e/ou bancos de dados. A maioria deles é de acesso gratuito, sendo os principais listados na Tabela 4.1.

\footnotetext{
Xiang (2006), Schwede et al. (2003).

Fan e Mark (2004).

Ginalski (2006).

Ginalski (2006), Baker e Šali (2001), Tress et al. (2005).

Baker e Šali (2001).

Venselaar et al. (2009).
} 
Tabela 4.1 Programas, servidores e bancos de dados úteis na modelagem por homologia estrutural.

\begin{tabular}{|c|c|c|c|}
\hline Ferramenta & Descrição & Endereço & Referência \\
\hline UniProt & $\begin{array}{l}\text { Banco de dados de informações } \\
\text { sobre sequência, função e proprie- } \\
\text { dades de proteínas. }\end{array}$ & $\begin{array}{l}<\text { www.uniprot. } \\
\text { org/> }\end{array}$ & $\begin{array}{c}\text { Bairoch e Apweiler (1997), } \\
\text { Bairoch e Boeckmann } \\
\text { (1994), } \\
\text { Magrane e Consortium } \\
\text { (2011) }\end{array}$ \\
\hline Protein NCBI & $\begin{array}{l}\text { Banco de dados de sequências } \\
\text { proteicas. }\end{array}$ & $\begin{array}{l}<\text { www.ncbi.nlm.nih. } \\
\text { gov/protein }>\end{array}$ & Pruitt et al. (2007) \\
\hline BRENDA & $\begin{array}{l}\text { Banco de dados para caracterização } \\
\text { enzimática, contendo informações } \\
\text { sobre a reação catalisada, assim } \\
\text { como parâmetros funcionais e } \\
\text { propriedades moleculares. }\end{array}$ & $\begin{array}{l}<\text { www.brenda- } \\
\text {-enzymes.org }>\end{array}$ & $\begin{array}{c}\text { Pharkya et al. (2003), Schom- } \\
\text { burg et al. }(2000,2013)\end{array}$ \\
\hline PDB & $\begin{array}{l}\text { Banco de dados de estruturas tri- } \\
\text { dimensionais de macromoléculas } \\
\text { advindas da aplicação de métodos } \\
\text { experimentais, como DRX. }\end{array}$ & $\begin{array}{c}<\text { www.rcsb.org/ } \\
\text { pdb }>\end{array}$ & $\begin{array}{c}\text { Berman et al. (2000), Berns- } \\
\text { tein et al. (1977) }\end{array}$ \\
\hline NCBI-BLAST & $\begin{array}{l}\text { Pacote disponível para identifi- } \\
\text { cação e seleção de moldes, assim } \\
\text { como alinhamento entre as sequ- } \\
\text { ências. }\end{array}$ & $\begin{array}{l}\text { <http://blast.ncbi. } \\
\text { nlm.nih.gov/Blast. } \\
\text { cgi> }\end{array}$ & Altschul et al. (1990) \\
\hline $\begin{array}{c}\text { FASTA } \\
\text { (ProteinData- } \\
\text { bases) }\end{array}$ & $\begin{array}{l}\text { Servidor para identificação e } \\
\text { seleção dos moldes, assim como } \\
\text { alinhamento entre as sequências. }\end{array}$ & $\begin{array}{l}<\text { www.ebi.ac.uk/ } \\
\text { Tools/sss/fasta/> }\end{array}$ & $\begin{array}{l}\text { Lipman e Pearson (1985), } \\
\text { Pearson }(1990,1991)\end{array}$ \\
\hline Clustal & $\begin{array}{l}\text { Servidor para alinhamento múl- } \\
\text { tiplo de sequências proteicas e de } \\
\text { ácidos nucleicos. }\end{array}$ & $<$ www.clustal.org/> & $\begin{array}{c}\text { Chenna et al. (2003), Higgins } \\
\text { e Sharp (1988), Larkin et } \\
\text { al. (2007), Thompson et al. } \\
\text { (1994) }\end{array}$ \\
\hline MultAlin & $\begin{array}{l}\text { Servidor para alinhamento múl- } \\
\text { tiplo de sequências proteicas e de } \\
\text { ácidos nucleicos. }\end{array}$ & $\begin{array}{l}<\text { http://multalin. } \\
\text { toulouse.inra.fr/ } \\
\text { multalin/> }\end{array}$ & Corpet (1988) \\
\hline MODELLER & $\begin{array}{l}\text { Software para construção de mo- } \\
\text { delos tridimensionais de proteínas } \\
\text { a partir de dados provenientes do } \\
\text { alinhamento. }\end{array}$ & $\begin{array}{l}<\text { http://salilab.org/ } \\
\text { modeller }>\end{array}$ & $\begin{array}{l}\text { Eswar et al. (2007), } \\
\text { Šali e Blundell (1993) }\end{array}$ \\
\hline $\begin{array}{l}\text { Swiss-PDB } \\
\text { viewer } \\
(\mathrm{SPDBv})\end{array}$ & $\begin{array}{l}\text { Aplicação voltada para a modela- } \\
\text { gem de proteínas, desde a identi- } \\
\text { ficação e seleção dos moldes até a } \\
\text { validação do modelo. }\end{array}$ & $\begin{array}{l}<\text { www.expasy.org/ } \\
\text { spdbv/> }\end{array}$ & $\begin{array}{l}\text { Guex et al. }(1999,2009) \\
\text { Guex e Peitsch }(1997)\end{array}$ \\
\hline $\begin{array}{l}\text { SWISS- } \\
\text {-MODEL }\end{array}$ & $\begin{array}{l}\text { Servidor para modelagem de pro- } \\
\text { teínas por homologia. }\end{array}$ & $\begin{array}{l}<\text { http://swissmodel. } \\
\text { expasy.org/works- } \\
\text { pace }>\end{array}$ & $\begin{array}{l}\text { Arnold et al. (2006), Schwede } \\
\text { et al. (2003), Guex et al. } \\
\text { (2009), Peitsch (1995) }\end{array}$ \\
\hline PROCHECK & $\begin{array}{l}\text { Software voltado para a avaliação } \\
\text { da qualidade estereoquímica de } \\
\text { estruturas proteicas. }\end{array}$ & $\begin{array}{c}<\text { www.ebi.ac.uk/ } \\
\text { thornton-srv/ } \\
\text { software/PROCHE- } \\
\text { CK/> }\end{array}$ & $\begin{array}{l}\text { Laskowski et al. (1993), } \\
\text { Morris et al. (1992) }\end{array}$ \\
\hline
\end{tabular}


Tabela 4.1 Continuação...

\begin{tabular}{|c|c|c|c|}
\hline Ferramenta & Descrição & Endereço & Referência \\
\hline Whatcheck & $\begin{array}{l}\text { Software útil na avaliação do mo- } \\
\text { delo, principalmente com relação } \\
\text { às características da cadeia princi- } \\
\text { pal, do empacotamento global, da } \\
\text { geometria e simetria. }\end{array}$ & $\begin{array}{c}\text { <http://swift.cmbi. } \\
\text { ru.nl/gv/whatche- } \\
\text { ck/> }\end{array}$ & Hooft et al. (1996) \\
\hline Verify3D & $\begin{array}{l}\text { Servidor para avaliação da quali- } \\
\text { dade estrutural por meio da análise } \\
\text { da compatibilidade do modelo } \\
\text { tridimensional com a estrutura } \\
\text { primária da proteína. }\end{array}$ & $\begin{array}{c}<\text { http://nihserver. } \\
\text { mbi.ucla.edu/ } \\
\text { Verify_3D/> }\end{array}$ & Eisenberg et al. (1997) \\
\hline
\end{tabular}

Bancos de dados $\quad$ Seleção dos moldes e alinhamento _ Construção do modelo _ Validação

Os modelos gerados pela técnica de modelagem comparativa possuem amplas aplicações, dependendo da qualidade apresentada, como já mencionado ${ }^{65} \mathrm{Co}-$ mumente, são aplicados em: (i) estudos de mutagênese sítio-direcionada para gerar mutantes úteis no teste de hipóteses funcionais; (ii) identificação de sítio ativo e sítios de ligação de cofatores em enzimas; (iii) estudo e desenvolvimento de ligantes de um dado sítio de ligação; (iv) modelagem da especificidade do substrato; (v) simulações de docking molecular enzima-ligante; (vi) interpretação de resultados experimentais; e (vii) refinamento de estruturas cristalográficas. ${ }^{66}$

No âmbito da descrição de estruturas tridimensionais de macromoléculas, uma importante aplicação dos modelos preditos por homologia estrutural é no refinamento de estruturas cristalográficas. ${ }^{67} \mathrm{O}$ padrão de difração é definido pela densidade eletrônica da macromolécula, a qual, por sua vez, depende da soma de todas as amplitudes e fases advindas das reflexões. ${ }^{68}$ No entanto, durante a detecção dos eventos de difração em uma análise por DRX, as informações sobre as fases são perdidas, originando o problema das fases. ${ }^{69}$ Neste contexto, os modelos preditos são aplicados de forma a auxiliar na solução deste problema em cristalografia, em que a modelagem por homologia pode ser utilizada como guia na determinação das fases. ${ }^{70} \mathrm{~A}$ utilização em conjunto da DRX e das técnicas de modelagem por homologia contribui grandemente para a descrição estrutural de macromoléculas, de forma a potencializar e acelerar a obtenção de estruturas tridimensionais de enzimas e demais biomoléculas com elevada precisão. ${ }^{71}$

Além do refinamento estrutural, a modelagem por homologia pode ser útil na geração de uma estrutura tridimensional aprimorada de enzimas e demais macromoléculas. Na estrutura descrita por DRX, alguns dados sobre resíduos específicos

65 Baker e Šali (2001), Ginalski (2006).

66 Baker e Šali (2001), Sánchez e Šali (2000).

67 Giorgetti et al. (2005), DiMaio et al. (2011), Qian et al. (2007).

68 Rhodes (2006), Giorgetti et al. (2005).

69 Rhodes (2006).

70 Zhang (2009), Qian et al. (2007), Claude et al. (2004).

71 Giorgetti et al. (2005), Claude et al. (2004), Jones (2001). 
podem ser perdidos, visto que algumas regiões apresentam desordens vibracionais e de ocupação, como as alças. ${ }^{72}$ Em particular, no caso das enzimas, as regiões das alças geralmente determinam a especificidade da macromolécula, já que fazem parte do sítio ativo e dos sítios de ligação. ${ }^{73}$ Nesse contexto, a modelagem por homologia pode ser aplicada na predição de regiões proteicas específicas: as alças e as cadeias laterais. ${ }^{74}$ Assim, modelos aprimorados de macromoléculas são gerados, nos quais estão contidos também os resíduos perdidos na estrutura cristalográfica. Um exemplo desse procedimento foi observado no estudo envolvendo a enzima ACCase no desenvolvimento de nanobiossensores, em que, durante a construção do sistema molecular para simulação, a estrutura tridimensional da ACCase foi obtida do repositório $\mathrm{PDB}$, e o software $\mathrm{SPDBv}$ foi utilizado para adicionar os resíduos não descritos na estrutura, obtendo um sistema mais aprimorado para estudos de DM e docking molecular. ${ }^{75}$

\subsubsection{Docking molecular}

A partir da descrição das coordenadas atômicas da biomolécula, ou seja, da obtenção do modelo tridimensional completo, parte-se para o estudo das interações intermoleculares, as quais podem descrever mecanismos-chave em processos biológicos. ${ }^{76}$ Essa tarefa pode ser realizada pela aplicação do docking molecular, uma estratégia computacional capaz de prever o modo de ligação entre moléculas em um complexo bioquímico, geralmente envolvendo uma designada como receptora (macromolécula) e outra menor designada como ligante. ${ }^{77}$ A definição da conformação possibilita, assim, a identificação do sítio de interação, bem como a quantificação da afinidade de ligação entre ambas. ${ }^{78} \mathrm{~A}$ técnica de docking é frequentemente aplicada para predizer a orientação de ligação de moléculas pequenas candidatas a fármacos em suas proteínas-alvo, a fim de estudar a afinidade e atividade de pequenas moléculas. ${ }^{79}$ Assim, o docking cumpre um papel importante no design racional de fármacos. ${ }^{80}$

A importância de se detalhar o modo pelo qual as moléculas e ligantes interagem entre si, para a medicina, consiste no entendimento dos mecanismos que regem o funcionamento normal do organismo, assim como o desenvolvimento de doenças.$^{81} \mathrm{~A}$ descrição do processo de reconhecimento molecular envolve a caracterização do grande número de interações intermoleculares entre o ligante, a mo-

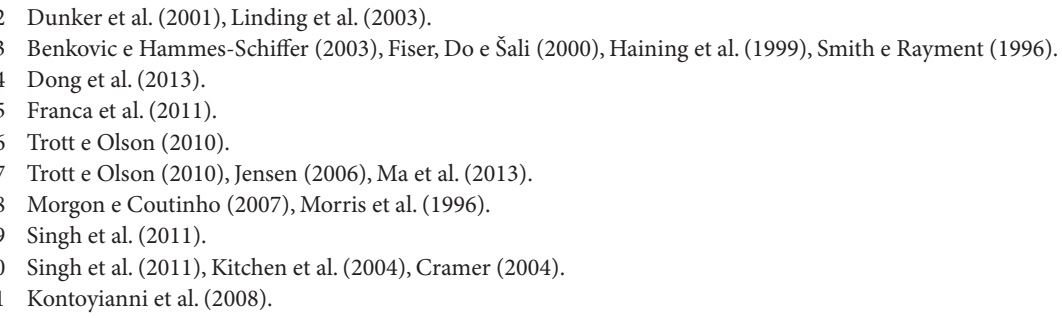


lécula receptora e o solvente.$^{82}$ Resumidamente, o problema de docking, dada sua elevada complexidade, pode ser dividido em dois subproblemas: (i) definição da orientação assumida pela molécula ligante no sítio de ligação do receptor, com base na aplicação de um algoritmo que promova buscas conformacionais guiadas por uma grade de energia em uma área delimitada da macromolécula; e (ii) utilizando a função scoring (por exemplo, aproximação da energia de ligação entre o receptor e o ligante), identificar a conformação do ligante com a mínima energia de ligação, a qual seja viável computacionalmente. ${ }^{83}$

As proteínas possuem estruturas que podem ser consideradas rígidas, e o ligante pode explorar livremente seu espaço conformacional. ${ }^{84}$ As conformações são geradas a partir dos cálculos de docking, em que o ligante é, então, acoplado sucessivamente na estrutura proteica. ${ }^{85}$ Nesses cálculos, a obtenção das energias de ligação é chave para a determinação das conformações. A descrição das energias de ligação é feita com base na energia livre de ligação de Gibbs $\left(\Delta G_{\text {lig }}\right)$, expressa pela Equação 4.1:86

$$
\Delta \mathrm{G}_{\text {lig }}=\Delta \mathrm{H}-\mathrm{T} \Delta \mathrm{S}=\mathrm{RT} \ln \mathrm{K}_{\mathrm{i}}
$$

em que $\Delta \mathrm{H}$ é a variação de entalpia, $T$ é a temperatura absoluta, $\Delta \mathrm{S}$ é a variação de entropia, $\mathrm{R}$ é a constante universal dos gases e $\mathrm{K}_{\mathrm{i}}$ é a constante de inibição (medida experimentalmente).

A obtenção dos valores de $\Delta \mathrm{G}_{\text {lig }}$ pode ser realizada pela aplicação de diversos métodos, desde aqueles com maior custo computacional e precisão, que empregam simulações de DM, aplicando um campo de força molecular clássico, ${ }^{87}$ tal como as metodologias que reduzem o custo computacional, calculando a energia com base em simulações de DM nos estados inicial, envolvendo o ligante em solução, e final, envolvendo o complexo receptor-ligante. ${ }^{88}$

Uma série de conformações aceitáveis que descrevem o complexo receptor-ligante é, assim, computada. Esse conjunto de orientações é submetido a funções de avaliação (scoring) para a determinação da pose mais favorável, ou seja, com a energia de ligação mínima. As funções de avaliação realizam aproximações e simplificações computacionais a fim de atingir um equilíbrio entre tempo gasto e precisão dos resultados durante o procedimento de avaliação das conformações aceitáveis. ${ }^{89}$ Existem três classes principais de funções de avaliação usadas em programas de docking: (i) com base em campos de força, os quais utilizam uma série de termos de interação derivados de fenômenos físico-químicos para avaliar a energia do sistema; (ii) empíricas, que consistem na soma de um conjunto de funções parametrizadas

82 Morgon e Coutinho (2007).

83 Trott e Olson (2010), Ma et al. (2013), Morgon e Coutinho (2007), Coupez e Lewis (2006), Halperin et al. (2002).

84 Trott e Olson (2010).

85 Trott e Olson (2010), Zsoldos et al. (2006).

86 Morgon e Coutinho (2007).

87 Morgon e Coutinho (2007), Kollman (1993), Van Gunsteren et al. (1994).

88 Morgon e Coutinho (2007).

89 Jensen (2006), Zsoldos et al. (2006). 
que reproduzem dados experimentais (por exemplo, energias de ligação ou conformações); e (iii) com base em conhecimentos que utilizam dados estatísticos derivados de informações experimentais de complexos proteína-ligante para a definição de interações favoráveis e, assim, classificar o conjunto de conformações. ${ }^{90} \mathrm{Em}$ suma, a Figura 4.7 sintetiza os passos de aplicação da técnica de docking.

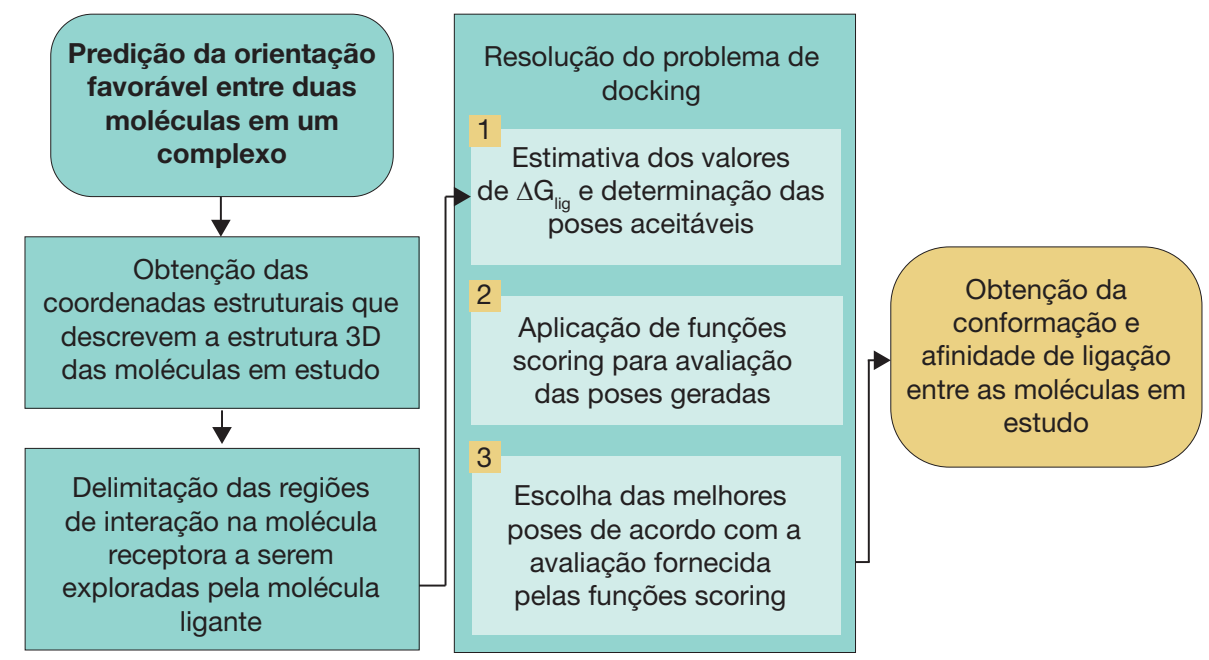

Figura 4.7 Fluxograma de aplicação do docking molecular.

O blind docking, outra modalidade de docking de grande relevância, foi introduzido para detecção de modos sítios de ligação de ligantes peptídicos por meio do escaneamento completo das proteínas-alvo. ${ }^{91}$ Algumas partes da proteína, dependendo do sequenciamento de aminoácidos, podem ser tão reativas quanto o sítio de ligação, e, com isso, a investigação de regiões catalíticas não específicas é importante, já que a orientação espacial da enzima nem sempre é favorável para interação com o sítio ativo, havendo casos em que o substrato interage com regiões não funcionais da enzima. Portanto, o blind docking se mostra importante para a investigação dessas regiões enzimáticas. ${ }^{92}$ Ademais, um método que tem sido bastante usado no meio científico é o essencial de dinâmica com distância restrita, em inglês Distance Constrained Essential Dynamics Method (DCED), o qual tem sido aplicado na geração de múltiplas estruturas de encaixe, denominadas autoestruturas. Essa abordagem evita a maioria dos cálculos por dinâmica molecular de alto custo e pode captar os movimentos essenciais envolvidos em um receptor flexível, representado por uma dinâmica de coarse-grained. ${ }^{93}$

\footnotetext{
90 Morgon e Coutinho (2007), Zsoldos et al. (2006).

91 Aita et al. (2010), Davis et al. (2009), Gueto et al. (2009), Hetényi e Van der Spoel (2011), Ferrara et al. ([2007] 2014).

92 Gueto et al. (2009), Davis et al. (2009), Hetényi e Van der Spoel (2011), Ferrara et al. ([2007] 2014).

93 Corpet (1988), Mustard e Ritchie (2005). Técnica que faz uso de modelos reduzidos, os quais não englobam detalhes atômicos na análise estrutural; todavia, dada a simplicidade, a velocidade de cálculo das avaliações de energia do sistema é expandida.
} 


\subsubsection{Dinâmica molecular}

As simulações de DM têm como base as leis clássicas da Mecânica e têm sido aplicadas em larga escala nos problemas encontrados em Física, Química, Ciência dos Materiais, Biologia e, recentemente, em campos da Nanociência. ${ }^{94}$ A metodologia de DM está fundamentada na resolução da equação de movimento de Newton para um sistema de $\mathrm{N}$ átomos, os quais são considerados partículas que podem interagir entre si (Equação 4.2): ${ }^{95}$

$$
F_{i}=m_{i} \frac{\partial^{2} r_{i}}{\partial t^{2}}, i=1,2, \ldots, N
$$

sendo $F_{i}$ a força, $m_{i}$ a massa, $r_{i}$ a posição de uma dada partícula i e $t$, o tempo.

As forças podem ser descritas pela derivada negativa de uma função potencial $\mathrm{V}\left(\mathrm{r}_{1}, \mathrm{r}_{2}, \ldots, \mathrm{r}_{\mathrm{N}}\right)$, conforme mostrado na Equação $4.3:{ }^{96}$

$$
F_{i}=-\frac{\partial \mathrm{V}}{\partial r_{i}}
$$

A descrição das forças envolvidas em um sistema molecular é realizada com base na energia potencial $\mathrm{V}$, ou seja, previamente à obtenção das forças deve-se calcular a energia potencial do sistema em questão. $\mathrm{O}$ cálculo da energia potencial é realizado com base em um campo de força, o qual é definido por um conjunto de potenciais de interação que descrevem a dinâmica do sistema. ${ }^{97} \mathrm{~A}$ equação de campo de força leva em conta as contribuições devidas às interações ligadas (ligação, angular e torção), bem como as interações não ligadas (Van der Waals e eletrostáticas). Tais contribuições são determinadas de energia por um conjunto de parâmetros empíricos usados pelo campo de força para calcular a contribuição de energia para cada tipo de interação para os tipos de átomos que são definidos no sistema molecular considerado. ${ }^{98}$

As equações são resolvidas simultaneamente, em pequenos passos de tempo da ordem de fentossegundos ( $1 \mathrm{fs}=10^{-15}$ segundos). Em uma típica simulação de DM, as coordenadas iniciais dos átomos são obtidas experimentalmente, ou, então, derivadas da modelagem estrutural, conforme descrito no item 4.2.1. Dessa maneira, por meio da integração da equação de Newton, a simulação de DM pode converter

94 Czajka et al. (1998).

95 Jensen (2006).

96 Id. ibid.

97 Jensen (2006), MacKerell et al. (1998), Adcock e McCammon (2006), Sotomayor e Schulten (2007), Daggett e Levitt (1993), Karplus e Petsko (1990).

98 Leach (2001). 
dados estáticos dessas técnicas em informações dinâmicas. ${ }^{99}$ Os quadros das coordenadas atômicas (obtidos a cada passo de tempo), combinados sequencialmente em conjuntos, são denominados trajetórias, resultando em detalhados filmes de como as moléculas se comportam no tempo, sob certas condições predefinidas. ${ }^{100}$

As etapas para uma simulação de DM, geralmente, podem ser descritas por: (i) geração das conformações iniciais do sistema, em que as coordenadas atômicas (provenientes de dados experimentais, de métodos de modelagem por homologia ou mesmo de informações de um complexo preditas pela aplicação de docking molecular) são utilizadas para a construção do ambiente inicial de simulação; (ii) minimização de energia, em que os átomos são reacomodados na caixa de simulação, de modo que os contatos atômicos próximos e as geometrias distorcidas são corrigidos; (iii) equilíbrio do sistema, em que o sistema é levado a valores específicos de temperatura, pressão e pH; (iv) cálculo da energia potencial, o qual é realizado em uma série de termos de interação (campo de força); (v) obtenção das forças pela diferenciação dos valores de energia potencial em relação à posição das partículas no sistema; (vi) atualização das posições e velocidades dos componentes do sistema a cada passo de tempo; (vii) repetição das etapas iv, v e vi, até completar o tempo total de simulação; e, por fim, (viii) obtenção da trajetória do sistema (isto é, conjunto de posições e velocidades dos átomos no tempo de simulação). ${ }^{101}$

As limitações da DM se relacionam ao tamanho da biomolécula simulada e ao limite de tempo da metodologia. Essas dificuldades não permitiriam uma simulação realística da maioria dos processos celulares, já que eles geralmente envolvem centenas de milhares de átomos e ocorrem em uma escala de tempo de milissegundos a segundos. ${ }^{102}$ Nesse contexto, para contornar as limitações de tamanho e tempo, a DM tem sido simplificada por meio dos métodos de coarse-grained, ${ }^{103} \mathrm{e}$ os processos biomoleculares têm sido acelerados pela aplicação de forças direcionadas, por métodos de SMD. ${ }^{104}$

\subsubsection{Cálculos híbridos de mecânica quântica e mecânica molecular}

A investigação de sistemas moleculares grandes é um ponto limitante para a aplicação de abordagens quânticas. Apesar de a DM fornecer uma boa aproximação sobre o comportamento de biomoléculas e complexos moleculares no tempo, a Física Clássica é limitada quanto à descrição de um sistema atômico com relação às suas propriedades eletrônicas. No entanto, a abordagem eletrônica é crucial para

\footnotetext{
99 MacKerell et al. (1998), Adcock e McCammon (2006), Sotomayor e Schulten (2007), Daggett e Levitt (1993), Karplus e Petsko (1990), Lee et al. (2009).

100 Lee et al. (2009).

101 Rapaport (2004), Friedman et al. (2013), Gonçalves (2012).

102 Griebel et al. (2007).

103 Shih et al. (2006), Arkhipov et al. (2006), Klein e Shinoda (2008).

104 Kosztin et al. (1999), Isralewitz et al. (2001), Park e Schulten (2004), Parravicini et al. (2010).
} 
detalhar as interações envolvidas na dinâmica de processos celulares (por exemplo, enzima-substrato, antígeno-anticorpo, proteína-ligante, entre outros). ${ }^{105}$ Nesse contexto, com o intuito de aprimorar a descrição computacional de sistemas moleculares, a aplicação concomitante de abordagens advindas da mecânica molecular e da mecânica quântica vem sendo feita com êxito na descrição de fenômenos de grande relevância na interface entre Química e Biologia. ${ }^{106}$

Basicamente, o emprego de cálculos híbridos de QM/MM envolve a divisão do sistema em duas regiões principais ${ }^{107}$ (Figura 4.8). A região menor, designada como região de QM, é tratada por Química Quântica (isto é, empregando um método que descreva a estrutura eletrônica das moléculas), e a outra, maior, designada por região de MM, é tratada por mecânica molecular (isto é, método que descreve as interações interatômicas com base em uma função de energia potencial, determinada por um campo de força). ${ }^{108} \mathrm{Em}$ razão do tratamento do sistema com base em abordagens diferentes, a energia total é, então, descrita pela Equação 4.4: ${ }^{109}$

$$
\mathrm{E}_{\mathrm{Tot}}=\mathrm{E}_{\mathrm{QM}}+\mathrm{E}_{\mathrm{MM}}+\mathrm{E}_{\mathrm{QM}, \mathrm{MM}}
$$

sendo $\mathrm{E}_{\mathrm{QM}}$ a energia na região de $\mathrm{QM}, \mathrm{E}_{\mathrm{MM}}$ a energia na região de $\mathrm{MM}$ e $\mathrm{E}_{\mathrm{QM}, \mathrm{MM}}$ a energia na interface entre ambas.

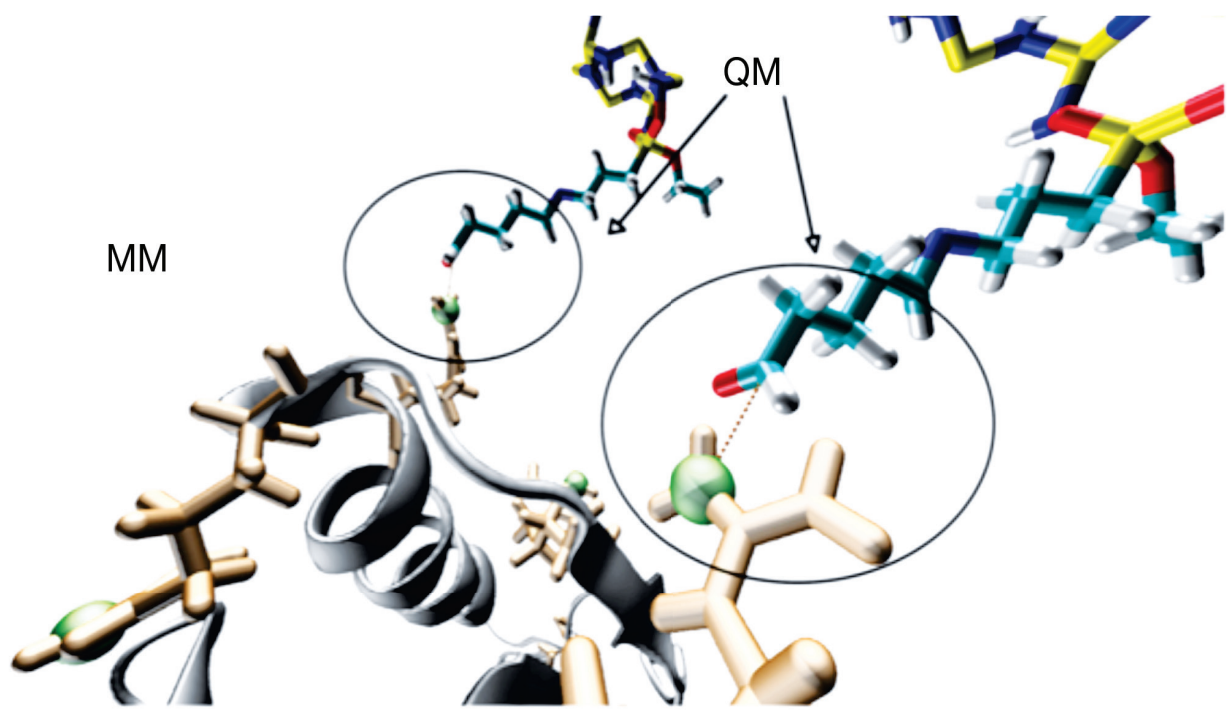

Figura 4.8 Descrição do sistema molecular com as interfaces das regiões QM e MM.

105 Menikarachchi e Gascon (2010)

106 Id. ibid.

107 Menikarachchi e Gascon (2010), Kang et al. (2012), Vreven et al. (2006).

108 Menikarachchi e Gascon (2010), Kang et al. (2012), Van der Kamp e Mulholland (2013).

109 Kang et al. (2012). 
A aplicação da abordagem QM/MM em um dado sistema depende das seguintes etapas: (i) seleção do método de QM empregado (dependente do processo molecular a ser caracterizado); (ii) seleção do campo de força utilizado nas análises de MM; (iii) divisão do sistema em regiões a serem tratadas por QM e MM (considerando as especificidades para a descrição computacional das regiões de interface entre elas); (iv) geração da estrutura tridimensional inicial para a descrição do sistema; e (v) definição do perfil de simulação (por exemplo, seleção de parâmetros, tempo de simulação, taxa de amostragem conformacional). ${ }^{110}$

Um dos pontos críticos na aplicação da metodologia de QM/MM é a definição da região a ser tratada por QM. Em razão da maior precisão desse método, supõe-se que quanto maior a região selecionada, melhor a qualidade dos resultados. No entanto, devem ser consideradas as limitações computacionais atuais, as quais restringem o tamanho da área de QM para o menor possível. ${ }^{111}$ Além disso, a precisa definição da fronteira entre os subsistemas e o modo como a energia é calculada é outro fator crucial no sucesso da aplicação dos cálculos híbridos, visto que as interações eletrostáticas, assim como os possíveis cortes de ligações químicas, devem ser consideradas. ${ }^{112}$

A interface pode ser fixada em uma região definida ou permitir seu movimento durante o curso da simulação, a fim de descrever processos como mudanças no sítio ativo e/ou movimento de íons solvatados. ${ }^{113} \mathrm{~A}$ escolha da região QM considera a precisão e confiabilidade versus o desprendimento computacional. Os métodos semiempíricos são os mais significativos e usados, porém o custo computacional ainda é alto. ${ }^{114}$ Em contrapartida, o método que usa a Teoria Funcional de Densidade (DFT) é uma alternativa em muitos estudos contemporâneos, fornecendo resultados com alta precisão em tempo menor, comparado com os métodos semiempíricos. ${ }^{115}$ $\mathrm{Na}$ região MM existem campos de força disponíveis para aplicações em biomoléculas, como, por exemplo, CHARMM, ${ }^{116}$ AMBER, ${ }^{117}$ GROMOS ${ }^{118}$ e OPLS, ${ }^{119}$ e para o tratamento de solventes explícitos, tais como TIP3 $\mathrm{P}^{120}$ ou SPC, ${ }^{121}$ no caso da água.

\subsubsection{Steered Molecular Dynamics (SMD)}

No estudo de certas propriedades de ligação e respostas biomoleculares a perturbações externas, é crescente o uso de metodologias fundamentadas na

\footnotetext{
110 Van der Kamp e Mulholland (2013), Senn e Thiel (2009).

111 Morgon e Coutinho (2007).

112 Senn e Thiel (2009).

113 Heyden et al. (2007).

114 Senn e Thiel (2009).

115 Id. ibid.

116 Brooks et al. (2009).

117 Christen et al. (2005).

118 Id. ibid.

119 Jorgensen et al. (1996).

120 Id. (1983).

121 Berendsen et al. (1981).
} 
aplicação de forças mecânicas em complexos biológicos, como a microscopia de força atômica. ${ }^{122}$ Nesse contexto, técnicas computacionais que reproduzem as forças envolvidas na remoção de uma dada molécula de um complexo estável são úteis na complementação e interpretação de resultados experimentais. ${ }^{123}$ Uma abordagem computacional muito utilizada para esse fim é a Dinâmica Molecular Direcionada (SMD, do inglês Steered Molecular Dynamics).

Uma simulação de SMD envolve a aplicação de uma força externa $F$ em um complexo macromolécula-ligante, induzindo a remoção deste último (Figura 4.9). De forma geral, a força $F$ é aplicada a um átomo (ou conjunto de átomos) de um sistema mecânico clássico regido pelo hamiltoniano $\mathrm{H}(\mathbf{r}, \mathrm{t})$, em que $\mathbf{r}$ especifica a configuração de todo o sistema e $t$ é o tempo. ${ }^{124} \mathrm{Na}$ formulação cv-SMD ("constant velocity SMD"), a força $F$ produz uma alteração concreta do sistema em um intervalo de tempo definido (isto é, com velocidade $v$ constante), conduzindo-o ao longo de uma coordenada generalizada $(\xi)$. No instante $t, F$ é expressa por: ${ }^{125}$

$$
\mathrm{F}(\mathrm{t})=\mathrm{k}\left(\xi_{0}+\mathrm{vt}-\xi^{\prime}\right)
$$

em que $k$ é constante de força, $\xi_{0}$ é o valor da coordenada generalizada em $\mathrm{t}=0$, $v$ é a velocidade e $\xi^{\prime}$ é o valor de $\xi$ no instante $t$. A integração de $\mathrm{F}(\mathrm{t})$ em relação a t resulta na computação do trabalho $\mathrm{W}(\mathrm{t})$, que, por sua vez, pode ser utilizado para calcular a diferença entre as energias livres dos estados $A$ e $B\left(G_{A}\right.$ e $G_{B}$, respectivamente) por meio da igualdade de Jarzynski, ${ }^{126}$

$$
\exp \left(-\frac{\Delta G}{k_{B} T}\right)=\left\langle\exp \left(\frac{W}{k_{B} T}\right)\right\rangle_{A}
$$

sendo $T$ a temperatura, $k_{\mathrm{B}}$ a constante de Boltzmann e $\Delta \mathrm{G}=\mathrm{G}_{\mathrm{B}}-\mathrm{G}_{\mathrm{A}}$; a expressão $\left\langle\exp \left(\frac{\mathrm{W}}{\mathrm{k}_{\mathrm{B}} \mathrm{T}}\right)\right\rangle_{\mathrm{A}}$ implica a média da quantidade entre parênteses angulares, realizada no estado inicial $A$. Identificando o estado A com $\xi_{0}(\xi$ em $t=0)$ e o estado B com $\xi$ no instante t, é possível reconstruir o perfil de $\Delta \mathrm{G}$ ao longo da coordenada generalizada $\xi$, isto é, o Potencial Médio de Força, $\mathrm{PMF} \equiv \Delta \mathrm{G}(\xi){ }^{127}$

De acordo com a Equação 4.6, o PMF, que é uma propriedade de sistemas em equilíbrio, pode ser extraído de simulações em regime de não equilíbrio, embora seja necessário um elevado número de réplicas, uma vez que está envolvida uma média exponencial. Contudo, o PMF pode ser satisfatoriamente reconstruído 
a partir da expansão cumulativa de segunda ordem da média exponencial, cujos acumuladores (ou armazenadores) são calculáveis com elevada exatidão, a partir de poucas réplicas, fornecendo, geralmente, um limite superior para o PMF. ${ }^{128}$

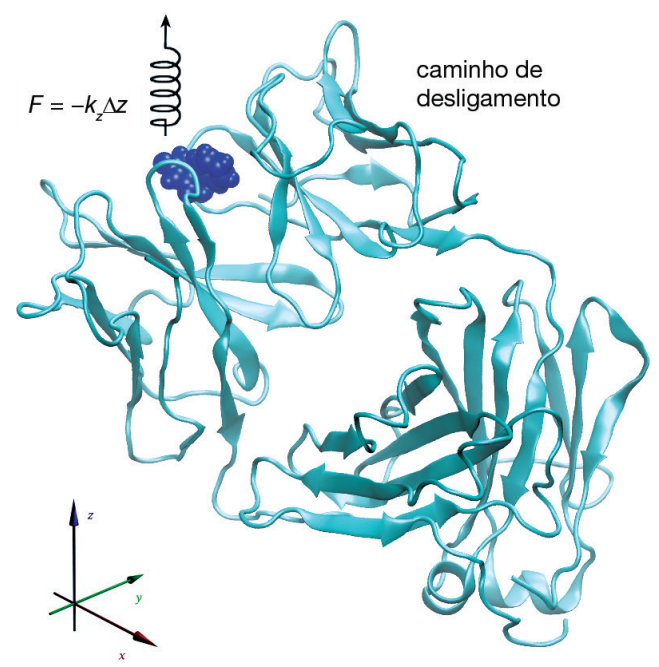

Figura 4.9 Representação da simulação utilizando SMD para retirada de uma molécula de antígeno do sítio de ligação do anticorpo. PDB ID: 1IGY.

Fonte: Franca et al. ${ }^{129}$

\subsection{APLICAÇÃO DAS TÉCNICAS COMPUTACIONAIS NOS ESTUDOS DE MICROSCOPIA DE FORÇA ATÔMICA E PANORAMA ATUAL DAS PESQUISAS}

O escopo das pesquisas do Grupo de Nanoneurobiofísica (GNN ${ }^{130}$ envolve o emprego da nanotecnologia no desenvolvimento de nanobiossensores, com base em pontas de AFM. A aplicabilidade desses nanodispositivos se expande desde o monitoramento de resíduos químicos provenientes da agricultura até o estudo do mecanismo de doenças complexas, tais como câncer, Alzheimer e Esclerose Múltipla (EM). Nesse contexto, as técnicas computacionais para a descrição do recobrimento de superfícies têm se mostrado cruciais para o melhor entendimento do mecanismo envolvido no sensoriamento mediado por esses nanodispositivos. Resultados promissores têm sido obtidos pela aplicação concomitante de metodologias experimentais com o AFM e abordagens computacionais. Alguns dos principais trabalhos serão detalhados nos parágrafos seguintes. 
Franca et al., ${ }^{131} \mathrm{em}$ 2011, utilizaram protocolos de modelagem por homologia, docking molecular e simulações de DM para assistir ao desenvolvimento de nanobiossensores empregando a enzima AcetilCoA carboxilase (ACCase). Foi observado que o dímero é a forma mais estável da enzima em solução aquosa, sendo a estrutura escolhida para a funcionalização. A partir dos cálculos computacionais, foram possibilitadas a identificação da área de imobilização da ACCase, na ponta do AFM, e a descrição da funcionalização. Ademais, a estratégia de docking caracterizou a interação entre o dímero da ACCase e as moléculas de herbicida (atrazina e diclofop). Em conjunto com simulações de DM e cálculos quânticos semiempíricos, foi observado que a ACCase interage preferencialmente com o diclofop, direcionando, assim, a construção do nanobiossensor. ${ }^{132}$

Em 2013, Deda et al. ${ }^{133}$ utilizaram a MMC na predição da orientação apropriada de biomoléculas sobre a ponta de AFM, a qual foi capaz de caracterizar a posição dos sítios ativos da enzima ALS, evidenciando presença de dois sítios ativos da enzima Acetolactato sintase (ALS) acessíveis para a interação com o inibidor (herbicida metsulfuron-methyl). Além disso, as técnicas de modelagem molecular apresentaram alta potencialidade para fornecer informações relacionadas à energia envolvida na interação enzima-herbicida, a predição do número de biomoléculas presentes na superfície da ponta, assim como informações extras, como quantas moléculas de herbicida interagem quando a ponta se aproxima do substrato. Os resultados preliminares indicaram a presença de, no máximo, nove biomoléculas na superfície de uma ponta com um raio de $20 \mathrm{~nm}$ (equivalente ao raio das pontas utilizadas nas experiências) livres para interação com as moléculas de herbicida. ${ }^{134}$ No entanto, estudos adicionais são necessários para corroborar esta hipótese.

Ainda em 2013, Oliveira et al. ${ }^{135}$ utilizaram simulações de DM para mimetizar a ponta do AFM funcionalizada, interagindo com a enzima, inicialmente modelada por Franca et al., ${ }^{136}$ em solução aquosa. Com os resultados de potencial eletrostático, foram propostas três possíveis orientações da enzima ACCase sobre a ponta do AFM. Os cálculos finais de DM revelaram que, após 50 ns de tempo de simulação, a geometria proteica preservou os sítios ativos da enzima ACCase para interagir com as moléculas de herbicidas no substrato. A análise do potencial eletrostático das interações enzima-ponta do AFM foi de grande importância na quantificação desse tipo de interação. As ligações de hidrogênio, que são interações fortes, puderam ser monitoradas em função do tempo. Outro parâmetro que pôde ser monitorado em razão da interação da enzima com a superfície recoberta pelo agente espaçador foi a integridade da enzima em termos de desnaturação. O gráfico de Ramachandran foi

131 Franca et al. (2011).

132 Id. ibid.

133 Deda et al. (2013).

134 Id. ibid.

135 Oliveira et al. (2013).

136 Franca et al. (2011). 
capaz de mostrar que, depois de uma simulação por DM extensa, a superfície não exerce influência suficiente para desnaturar a enzima.

Em 2014 foi publicado por Bueno et al. ${ }^{137}$ um estudo detalhando o processo de funcionalização em escala atômica com base em ferramentas computacionais. Enquanto, experimentalmente, estudos de AFM proporcionaram o desenvolvimento de um nanobiossensor para a detecção do diclofop, foi verificada computacionalmente a influência do processo de funcionalização na integridade das moléculas. Nesse processo, sendo as moléculas de herbicida ligadas ao APTES em conjunto com glutaraldeído para imobilização no substrato, foi estudada a possível influência desse sistema na capacidade do herbicida de inibir a ACCase. A interação entre o sistema herbicida+glutaraldeído+APTES e a enzima ACCase foi representada com base nas coordenadas cristalográficas disponíveis online, e as simulações computacionais mostraram que, com base nos resultados de energia de interação, o diclofop mantém suas características de inibição enzimática após imobilização. ${ }^{138}$

Ainda nessa linha de pesquisa, em 2014, Amarante et al. ${ }^{139}$ propuseram um modelo para descrição do recobrimento da superfície da ponta de AFM no nanobiossensor desenvolvido por Bueno et al., ${ }^{140}$ tal como obtiveram teoricamente os valores da força de interação ACCase-diclofop. O modelo para descrição do recobrimento da ponta de AFM envolveu uma abordagem estocástica, em que as moléculas de enzima foram representadas por poliedros rígidos. Foi estimado, por esse modelo, o número de enzimas adsorvidas na ponta de AFM, de acordo com seu raio. Por essa estimativa, também foi possível quantificar os sítios ativos disponíveis para interação com o herbicida, após a imobilização da ACCase na superfície. Ademais, a aplicação da metodologia de SMD permitiu mensurar as forças teóricas de interação enzima-herbicida, as quais se equipararam àquelas medidas experimentalmente por Bueno et al. ${ }^{141}$

As técnicas computacionais também foram úteis na descrição dos eventos moleculares relevantes na interação entre a enzima 4-hidroxifenil piruvato (HPPD) e o herbicida mesotriona, no qual as energias de interação entre tais moléculas foram mensuradas a partir do sítio de interação computado para esse sistema. Esses dados foram úteis na caracterização da interação HPPD-mesotriona, durante o desenvolvimento de nanobiossensor de ponta de AFM específico por Garcia et al. ${ }^{142}$

A MMC, além das aplicações supracitadas, tem sido utilizada com sucesso para a descrição de eventos específicos, como o reconhecimento molecular e a interação antígeno-anticorpo. ${ }^{143} \mathrm{~A}$ modelagem da especificidade das regiões variáveis de anticorpos também tem sido reportada na literatura, assim como o estabelecimento de protocolos computacionais para estudo de estruturas de tais macromo-

\footnotetext{
137 Bueno et al. (2014).

138 Id. ibid.

139 Amarante et al. (2014).

140 Bueno et al. (2014).

141 Id. ibid.

142 Garcia et al. (2015).

143 Yuan et al. (2012), Mulyanto (2011), Hanasaki et al. (2008), Carreño et al. (2008), Mikulska et al. (2011).
} 
léculas. ${ }^{144}$ Nesse panorama, considerando a elevada especificidade dos anticorpos e também seu papel como biomarcador de determinadas doenças, como a neuromielite óptica, ${ }^{145}$ a construção de nanossensores com base em anticorpos mostra-se promissora para o desenvolvimento de técnicas de diagnóstico mais precisas. Com os nanobiossensores envolvendo outras biomoléculas, como no caso dos anticorpos, a MMC deve, concomitantemente, descrever o recobrimento de pontas de AFM, considerando essas novas biomoléculas nos modelos, e, assim, futuramente, desenvolver novos protocolos de caracterização de superfícies.

\subsection{CONSIDERAÇõES FINAIS}

Neste capítulo foram mostradas algumas das principais metodologias computacionais aplicadas na descrição dos processos bioquímicos envolvidos no desenvolvimento de nanobiossensores. Tais metodologias, em conjunto, constituem protocolos específicos que são capazes de reproduzir, em escala atomística, os eventos contidos no processo de funcionalização de pontas de AFM. As abordagens computacionais são capazes de auxiliar de forma crucial na interpretação e no refinamento dos resultados obtidos experimentalmente, de forma a direcionar o desenvolvimento de nanobiossensores.

$\mathrm{O}$ uso de nanobiossensores tem mostrado grande potencialidade na área ambiental, conforme estudos publicados pelo GNN da UFSCar do campus de Sorocaba. Tais estudos abrem novas perspectivas para a aplicação desses dispositivos para fins biomédicos, por exemplo, a descrição de mecanismos moleculares e novas técnicas de diagnóstico e tratamento de doenças. Nesse contexto, várias aplicações das técnicas computacionais vêm sendo descritas na literatura, conforme também revisado no capítulo, o que faz das técnicas computacionais ferramentas importantes para as investigações de processos biológicos envolvidos no desenvolvimento de doenças.

O maior problema em reproduzir experimentos de AFM computacionalmente se refere ao tempo limitado de simulação, já que abrange um espaço temporal muito menor do que aquele envolvido na interação entre as moléculas funcionalizadas e o substrato. De forma geral, à medida que os computadores vão se aprimorando, tempos maiores de simulação vão se tornando possíveis, e os resultados dos cálculos teóricos vão se aproximando cada vez mais dos resultados experimentais. Com isso, o custo de funcionalização de pontas de AFM por meio de conhecimento prévio pelos computadores é reduzido.

144 Sircar (2012), Burkovitz et al. (2013), Almagro et al. (2011), Kurella e Gali (2014), Zhang et al. (2013)

145 Bennett et al. (2009), Graber et al. (2008). 


\section{REFERÊNCIAS}

Adcock, S. A.; McCammon, J. A. Molecular dynamics: survey of methods for simulating the activity of proteins. Chemical Reviews, v. 106, n. 5, p. 1589-1615, maio 2006.

Aita, T.; Nishigaki, K.; Husimi, Y. Toward the fast blind docking of a peptide to a target protein by using a four-body statistical pseudo-potential. Computational Biology and Chemistry, v. 34, n. 1, p. 53-62, fev. 2010.

Alberts, B. et al. Molecular biology of the cell. 5. ed. Nova York: Garland Science, 2007.

Almagro, J. C. et al. Antibody modeling assessment. Proteins, v. 79, n. 11, p. 3050-3066, nov. 2011.

Altschul, S. F. Amino acid substitution matrices from an information theoretic perspective. J Mol Biol, v. 219, p. 555-565, jun. 1991.

Altschul, S. F. et al. Basic local alignment search tool. J Mol Biol, v. 215, 403410, out. 1990.

Amarante, A. M. et al. Modeling the coverage of an AFM tip by enzyme and its application in nanobiosensors. Journal of Molecular Graphics \& Modelling, 2014.

AмAтo, I. Nanotechnology: shaping the world atom by atom. NTSC Report. 1999. Disponível em: <http://itri.loyola.edu/nano/IWGN.Public.Brochure/>. Acesso em: 23 jul. 2016.

Arkhipov, A. et al. Coarse-grained molecular dynamics simulations of a rotating bacterial flagellum. Biophysical Journal, v. 91, n. 12, p. 4589-4597, 15 dez. 2006.

Arnautova, Y. A.; Abagyan, R. A.; Totrov, M. Development of a new physics-based internal coordinate mechanics force field and its application to protein loop modeling. Proteins, v. 79, p. 477-498, fev. 2011.

ARNOLD, K. et al. The SWISS-MODEL workspace: a web-based environment for protein structure homology modelling. Bioinformatics, v. 22, p. 195-201, jan. 2006.

BAIroch, A.; ApweIler, R. The SWISS-PROT protein sequence database: its relevance to human molecular medical research. J Mol Med, Berlim, v. 75, p. 312-316, maio 1997.

Bairoch, A.; Boeckmann, B. The SWISS-PROT protein sequence data bank: current status. Nucleic Acids Res, v. 22, p. 3578-3580, set. 1994.

BAKER, D.; ŠAlI, A. Protein structure prediction and structural genomics. Science, v. 294, p. 93-96, out. 2001.

Benkovic, S. J.; Hammes-Schiffer, S. A perspective on enzyme catalysis. Science, v. 301, p. 1196-1202, ago. 2003.

BennetT, J. L. et al. Intrathecal pathogenic anti-aquaporin-4 antibodies in early neuromyelitis optica. Annals of Neurology, v. 66, n. 5, p. 617-629, nov. 2009.

Berendsen, H. J. C. et al. Interaction models for water in relation to protein hydration. In: Pullman, B. (Ed.). Intermolecular forces: the Jerusalem Symposia on Quantum Chemistry and Biochemistry. [S.1.]: Springer Netherlands, 1981. p. 331-342.

Berman, H. M. et al. The protein data bank. Nucleic Acids Res, v. 28, p. 235-242, jan. 2000. 
BERnSTEIN, F. C. et al. The protein data bank: a computer-based archival file for macromolecular structures. J Mol Biol, v. 112, p. 535-542, maio 1977.

Binnig, G.; Quate, C. F.; Gerber, C. Atomic force microscope. Physical Review Letters, v. 56, n. 9, p. 930-933, 03 mar. 1986.

Binnig, G.; Rohrer, H. Scanning tunneling microscopy. Surface Science, v. 126, n. 1-3, p. 236-244, 02 mar. 1983.

Bower, M. J.; Cohen, F. E.; Dunbrack, R. L. Prediction of protein side-chain rotamers from a backbone-dependent rotamer library: a new homology modeling tool. J Mol Biol, v. 267, p. 1268-1282, abr. 1997.

Brooks, B. R. et al. CHARMM: the biomolecular simulation program. Journal of Computational Chemistry, v. 30, n. 10, p. 1545-1614, 30 jul. 2009.

Bueno, C. C. et al. Nanobiosensor for diclofop detection based on chemically modified AFM probes. IEEE Sensor Journal, 2014.

Burkovitz, A. et al. Computational identification of antigen-binding antibody fragments. Journal of Immunology, Baltimore, v. 190, n. 5, p. 2327-2334, 01 mar. 2013.

Butt, H. J.; Downing, K. H.; Hansma, P. K. Imaging the membrane protein bacteriorhodopsin with the atomic force microscope. Biophysical Journal, v. 58, n. 6, p. 1473-1480, dez. 1990.

CARreño, R. et al. A mechanism for antibody-mediated outside-in activation of LFA-1. The Journal of Biological Chemistry, v. 283, n. 16, p. 10642-10648, 18 abr. 2008.

CAse, D. A et al. AMBER. São Francisco: University of California, 2008.

CAstro Bueno, C. et al. Nanobiosensor for diclofop detection based on chemically modified AFM probes. IEEE Sensors Journal, v. 14, n. 5, p. 1467-1475, maio 2014.

Chenna, R. et al. Multiple sequence alignment with the Clustal series of programs. Nucleic Acids Res, v. 31, p. 3497-3500, jul. 2003.

Сhipot, C.; Pohorille, A. Free energy calculations: theory and applications in chemistry and biology. Nova York: Springer, 2007.

Christen, M. et al. The GROMOS software for biomolecular simulation: GROMOS05. Journal of Computational Chemistry, v. 26, n. 16, p. 1719-1751, dez. 2005.

Claude, J. B. et al. CaspR: a web server for automated molecular replacement using homology modelling. Nucleic Acids Res, v. 32, p. W606-W609, jul. 2004.

Contreras-Moreira, B.; Fitzjohn, P. W.; Bates, P. A. Comparative modelling: an essential methodology for protein structure prediction in the post-genomic era. Appl Bioinformatics, v. 1, p. 177-190, 2002.

CORPET, F. Multiple sequence alignment with hierarchical clustering. Nucleic Acids Res, v. 16, p. 10881-10890, nov. 1988.

Coupez, B.; LewIs, R. A. Docking and scoring: theoretically easy, practically impossible? Current Medicinal Chemistry, v. 13, n. 25, p. 2995-3003, 2006. 
Cramer, C. J. Essentials of computational chemistry: theories and models. 2. ed. Chichester: John Wiley \& Sons, 2004.

Czajka, R.; Jurczyszyn, L.; RafiI-TABar, H. Surface physics at the nano-scale via scanning probe microscopy and molecular dynamics simulations. Progress in Surface Science, v. 59, n. 1-4, p. 13-23, 1998.

DA Silva, A. C. N. et al. Nanobiosensors based on chemically modified AFM probes: a useful tool for metsulfuron-methyl detection. Sensors, Basileia, v. 13, n. 2, p. 1477-1489, 24 jan. 2013.

. Nanobiosensors exploiting specific interactions between an enzyme and herbicides in atomic force spectroscopy. Journal of Nanoscience and Nanotechnology, v. 14, n. 9, p. 6678-6684, 01 set. 2014.

Daga, P. R.; Patel, R. Y.; Doerksen, R. J. Template-based protein modeling: recent methodological advances. Curr Top Med Chem, v. 10, p. 84-94, 2010.

Daggett, V.; Levitt, M. Realistic simulations of native-protein dynamics in solution and beyond. Annual Review of Biophysics and Biomolecular Structure, v. 22, n. 1, p. 353-380, 1993.

Davis, A. M.; Teague, S. J.; Kleywegt, G. J. Application and limitations of X-ray crystallographic data in structure-based ligand and drug design. Angew Chem Int Ed Engl, v. 42, p. 2718-2736, jun. 2003.

DAvis, I. W. et al. Blind docking of pharmaceutically relevant compounds using RosettaLigand. Protein Science: a publication of the Protein Society, v. 18, n. 9, p. 1998-2002, set. 2009.

DEDA, D. K. et al. The use of functionalized AFM tips as molecular sensors in the detection of pesticides. Materials Research, São Carlos, v. 16, n. 3, p. 683-687, jun. 2013.

DiMAio, F. et al. Improved molecular replacement by density-and energy-guided protein structure optimization. Nature, v. 473, p. 540-543, maio 2011.

Dong, G. Q. et al. Optimized atomic statistical potentials: assessment of protein interfaces and loops. Bioinformatics, set. 2013.

Dunker, A. K. et al. Intrinsically disordered protein. J Mol Graph Model, v. 19, p. 26-59, 2001.

EIgler, D. M.; Schweizer, E. K. Positioning single atoms with a scanning tunnelling microscope. Nature, v. 344, n. 6266, p. 524-526, 05 abr. 1990.

EIsenberg, D.; Luthy, R.; Bowie, J. U. VERIFY3D: assessment of protein models with three-dimensional profiles. Methods Enzymol, v. 277, p. 396-404, 1997.

Eswar, N. et al. Comparative protein structure modeling using MODELLER. Curr Protoc Protein Sci, nov. 2007. (v. chapter 2, p. unit 2 9).

Etchegaray, A.; Bueno, C. C.; Teschke, O. Identification of microcistin LR at the molecular level using atomic force microscopy. Química Nova, v. 33, n. 9, p. 1843-1848, jan. 2010.

FAN, H. Virtual ligand screening against comparative models of proteins. In: Ruso, J. M.; Piñero, A. (Ed.). Proteins in solution and at interfaces: methods and applications in biotechnology and materials science. 1. ed. Hoboken: John Wiley \& Sons, 2013. p. 179-192. 
FAn, H.; Mark, A. E. Refinement of homology-based protein structures by molecular dynamics simulation techniques. Protein Sci, v. 13, p. 211-220, jan. 2004.

Ferrara, J. T.; Rosales, M. C.; Basurto, J. C. Homology modeling and blind docking approach studies of pig heart fumarase. 2007. Disponível em: <http://www.redalyc.org/ resumen.oa?id=47551305>. Acesso em: 12 ago. 2014.

FISER, A.; Do, R. K.; ŠALI, A. Modeling of loops in protein structures. Protein Sci, v. 9, p. 1753-1773, set. 2000.

FISER, A.; ŠALI, A. ModLoop: automated modeling of loops in protein structures. Bioinformatics, v. 19, p. 2500-2501, dez. 2003.

Franca, E. F.; Amarante, A. M.; Leite, F. L. Introduction to atomic force microscopy simulation. In: MÉndez-Vilas, A.; Díaz, J. Microscopy: science, technology, applications and education. 1. ed. Badajoz: Formatex Research Center, 2010. v. 2, p. 1338-1349.

FrancA, E. F. et al. Designing an enzyme-based nanobiosensor using molecular modeling techniques. Phys Chem Chem Phys, v. 13, p. 8894-8899, maio 2011.

Friedman, R.; Boye, K.; Flatmark, K. Molecular modelling and simulations in cancer research. Biochim Biophys Acta, v. 1836, n. 1, p. 1-14, ago. 2013.

GARCiA, P. S. et al. A nanobiosensor based on 4-hydroxyphenylpyruvate dioxygenase enzyme for mesotrione detection. IEEE Sensors Journal, v. 15, n. 4, p. 2106-2113, abr. 2015.

García, R.; PÉrez, R. Dynamic atomic force microscopy methods. Surface Science Reports, v. 47, n. 6-8, p. 197-301, set. 2002.

Garrett, R. H.; Grisham, C. M. Biochemistry. 5. ed. Belmont: Cengage Learning, 2013.

GinAlski, K. Comparative modeling for protein structure prediction. Curr Opin Struct Biol, v. 16, p. 172-177, abr. 2006.

Giorgetti, A. et al. Evaluating the usefulness of protein structure models for molecular replacement. Bioinformatics, v. 21, supl. 2, p. ii72-ii76, set. 2005.

GonçAlves, R. B. Modelagem teórica e computacional de dendrímeros para o transporte de tuberculostáticos. Tese de Doutorado. Pontifícia Universidade Católica do Rio de Janeiro, Rio de Janeiro, 2012.

Graber, D. J. et al. Neuromyelitis optica pathogenesis and aquaporin 4. Journal of Neuroinflammation, v. 5, p. 22, 2008.

Griebel, M.; KnAPeK, S.; Zumbusch, G. Numerical simulation in molecular dynamics: numerics, algorithms, parallelization, applications. Heidelberg: Springer, 2007. v. 5.

Gueto, C.; Torres, J.; Vivas-Reyes, R. CoMFA, LeapFrog and blind docking studies on sulfonanilide derivatives acting as selective aromatase expression regulators. European Journal of Medicinal Chemistry, v. 44, n. 9, p. 3445-3451, set. 2009.

Guex, N.; Diemand, A.; Peitsch, M. C. Protein modelling for all. Trends in Biochemical Sciences, v. 24, p. 364-367, 1999. 
Guex, N.; Peitsch, M. C. SWISS-MODEL and the Swiss-PdbViewer: an environment for comparative protein modeling. Electrophoresis, v. 18, p. 2714-2723, dez. 1997.

Guex, N.; Peitsch, M. C.; Schwede, T. Automated comparative protein structure modeling with SWISS-MODEL and Swiss-PdbViewer: a historical perspective. Electrophoresis, v. 30, supl. 1, p. S162-S173, jun. 2009.

HAINING, R. L. et al. Enzymatic determinants of the substrate specificity of CYP2C9: role of B'-C loop residues in providing the pi-stacking anchor site for warfarin binding. Biochemistry, v. 38, p. 3285-3292, mar. 1999.

Halperin, I. et al. Principles of docking: an overview of search algorithms and a guide to scoring functions. Proteins: Structure, Function, and Bioinformatics, v. 47, n. 4, p. 409-443, 01 jun. 2002.

Hanasaki, I.; Haga, T.; Kawano, S. The antigen-antibody unbinding process through steered molecular dynamics of a complex of an Fv fragment and lysozyme. Journal of Physics: Condensed Matter, v. 20, n. 25, 255-238, 25 jun. 2008.

Hermans, R. I. Atomic force microscopy in liquid. In: Bar, A. M.; Reifenberger, R. G. (Ed.). Atomic force microscopy in liquid. [S.l.]: Wiley-VCH, 2012. p. 157-184.

Hetényi, C.; VAn der Spoel, D. Toward prediction of functional protein pockets using blind docking and pocket search algorithms. Protein Science: a Publication of the Protein Society, v. 20, n. 5, p. 880-893, maio 2011.

Heyden, A.; Lin, H.; Truhlar, D. G. Adaptive partitioning in combined quantum mechanical and molecular mechanical calculations of potential energy functions for multiscale simulations. The Journal of Physical Chemistry, B, v. 111, n. 9, p. 2231-2241, 08 mar. 2007.

Higgins, D. G.; SHARP, P. M. CLUSTAL: a package for performing multiple sequence alignment on a microcomputer. Gene, v. 73, p. 237-244, dez. 1988.

Hooft, R. et al. Errors in protein structures. Nature, v. 381, p. 272, 1996.

Hummer, G.; Szabo, A. Free energy reconstruction from nonequilibrium single-molecule pulling experiments. Proceedings of the National Academy of Sciences of the United States of America, v. 98, n. 7, p. 3658-3661, 27 mar. 2001.

Kinetics from nonequilibrium single-molecule pulling experiments. Biophysical Journal, v. 85, n. 1, p. 5-15, jul. 2003.

IsRalewitz, B.; GAO, M.; SCHUlten, K. Steered molecular dynamics and mechanical functions of proteins. Current Opinion in Structural Biology, v. 11, n. 2, p. 224-230, abr. 2001.

Izrailev, S. et al. Steered molecular dynamics. In: Deuflhard, P. et al. (Ed.). Computational molecular dynamics: challenges, methods, ideas. Lecture notes in computational science and engineering. [S.1.]: Springer Berlin Heidelberg, 1999. p. 39-65.

JARZynski, C. Nonequilibrium equality for free energy differences. Phys. Rev. Lett., v. 78, n. 14, p. 2690-2693, 1997a.

. Equilibrium free-energy differences from nonequilibrium measurements: A master-equation approach. Phys. Rev. E, v. 56, n. 5, p. 5018-5035, 1997 b. 
JENSEN, F. Introduction to computational chemistry. 2. ed. [S.l.]: Wiley, 2006.

Jensen, M. O. et al. Energetics of glycerol conduction through aquaglyceroporin GlpF. Proceedings of the National Academy of Sciences of the United States of America, v. 99, n. 10, p. 6731-6736, 14 maio 2002.

JonEs, D. T. Evaluating the potential of using fold-recognition models for molecular replacement. Acta Crystallogr D Biol Crystallogr, v. 57, p. 1428-1434, out. 2001.

Jorgensen, W.; Maxwell, D.; Tiradorives, J. Development and testing of the OPLS all-atom force field on conformational energetics and properties of organic liquids. Journal of the American Chemical Society, v. 118, n. 45, p. 11225-11236, 1996.

Jorgensen, W. L. et al. Comparison of simple potential functions for simulating liquid water. The Journal of Chemical Physics, v. 79, n. 2, p. 926-935, 1983.

Kang, J.; Hagiwara, Y.; Tateno, M. Biological applications of hybrid quantum mechanics/molecular mechanics calculation. BioMed Research International, v. 2012, p. 1-11, 28 mar. 2012.

Karplus, M.; Petsko, G. A. Molecular dynamics simulations in biology. Nature, v. 347, n. 6294, p. 631-639, 18 out. 1990.

Kendrew, J. C. et al. A three-dimensional model of the myoglobin molecule obtained by x-ray analysis. Nature, v. 181, p. 662-668, mar. 1958.

Kessel, A.; Ben-TAL, N. Introduction to proteins: structure, function, and motion. 1. ed. Boca Raton: CRC Press, 2011.

Kinch, L. N.; Grishin, N. V. Evolution of protein structures and functions. Curr Opin Struct Biol, v. 12, p. 400-408, jun. 2002.

Kitchen, D. B. et al. Docking and scoring in virtual screening for drug discovery: methods and applications. Nature reviews. Drug Discovery, v. 3, n. 11, p. 935-949, nov. 2004.

KLein, M. L.; ShinodA, W. Large-scale molecular dynamics simulations of self-assembling systems. Science, v. 321, n. 5890, p. 798-800, 08 ago. 2008.

Kollman, P. Free energy calculations: applications to chemical and biochemical phenomena. Chemical Reviews, v. 93, n. 7, p. 2395-2417, 01 nov. 1993.

Kontoyianni, M. et al. Theoretical and practical considerations in virtual screening: a beaten field? Current Medicinal Chemistry, v. 15, n. 2, p. 107-116, 2008.

Kosztin, D.; Izrailev, S.; Schulten, K. Unbinding of retinoic acid from its receptor studied by steered molecular dynamics. Biophysical Journal, v. 76, p. 188-197, 1999.

Kumar, S.; Filipski, A. Multiple sequence alignment: in pursuit of homologous DNA positions. Genome Res, v. 17, p. 127-135, fev. 2007.

KuRELla, V. B.; Gali, R. Structure guided homology model based design and engineering of mouse antibodies for humanization. Bioinformation, v. 10, n. 4, p. 180-186, 2014.

LARKIN, M. A. et al. Clustal W and clustal X version 2.0. Bioinformatics, v. 23, p. 2947-2948, nov. 2007. 
LAsKOWsKI, R. et al. PROCHECK: a program to check the stereochemical quality of protein structures. Journal of Applied Crystallography, v. 26, p. 283-291, abr. 1993.

LEACH, A. Molecular modelling: principles and applications. 2. ed. [S.1.]: Prentice Hall, 2001. LEE, E. H. et al. Discovery through the computational microscope. Structure, Londres, v. 17, n. 10 , p. $1295-1306,14$ out. 2009.

Leite, F. L.; Hausen, M.; Oliveira, G. S.; Brum, D. G.; Oliveira, O. N. Nanoneurobiophysics: new challenges for diagnosis and therapy of neurologic disorders. Nanomedicine, Londres, v. 10, n. 23, p. 3417-3419, 2015.

Linding, R. et al. Protein disorder prediction: implications for structural proteomics. Structure, v. 11, p. 1453-1459, nov. 2003.

Lipman, D. J.; Pearson, W. R. Rapid and sensitive protein similarity searches. Science, v. 227, p. 1435-1441, mar. 1985.

Lyubchenko, Y. L. et al. Atomic force microscopy of DNA and bacteriophage in air, water and propanol: the role of adhesion forces. Nucleic Acids Research, v. 21, n. 5, p. 1117-1123, 11 mar. 1993.

MA, R. et al. Mutual artificial bee colony algorithm for molecular docking. International Journal of Biomathematics, v. 6, n. 6, p. 1350038-11, set. 2013.

MacKerell, A. D. et al. All-atom empirical potential for molecular modeling and dynamics studies of proteins. Journal of Physical Chemistry, B, v. 102, n. 18, p. 3586-3616, 1998.

Magrane, M.; Consortium, U. UniProt knowledgebase: a hub of integrated protein data. Database, Oxford, v. 2011, p. 1-11, 2011.

MenikarachCHI, L.; GAsCON, J. QM/MM Approaches in medicinal chemistry research. Current Topics in Medicinal Chemistry, v. 10, n. 1, p. 46-54, 01 jan. 2010.

Meyer, E. Atomic force microscopy. Progress in Surface Science, v. 41, n. 1, p. 3-49, set. 1992. Mikulska, K.; PepŁowski, L.; Nowak, W. Nanomechanics of Ig-like domains of human contactin (BIG-2). Journal of Molecular Modeling, v. 17, n. 9, p. 2313-2323, set. 2011.

Morgon, N.; Coutinho, K. Métodos de química teórica e modelagem molecular. 1. ed. São Paulo: Livraria da Física, 2007.

Morris, A. L. et al. Stereochemical quality of protein structure coordinates. Proteins, v. 12, p. 345-364, abr. 1992.

Morris, G. M. et al. Distributed automated docking of flexible ligands to proteins: Parallel applications of AutoDock 2.4. Journal of Computer-Aided Molecular Design, v. 10, n. 4, p. 293-304, 01 ago. 1996.

Mulyanto, C. C. Prediction of a neutralizing epitope of a H5N1 virus hemagglutinin complexed with an antibody variable fragment using molecular dynamics simulation. Journal of Biophysical Chemistry, v. 2, n. 3, p. 258-267, 2011.

Mustard, D.; Ritchie, D. W. Docking essential dynamics eigenstructures. Proteins, v. 60, n. 2, p. 269-274, 01 ago. 2005. 
Myerson, A. S. Molecular modeling applications in crystallization. 1. ed. Nova York: Cambridge University Press, 1999.

Nelson, D. L.; Cox, M. M. Lehninger principles of biochemistry. 5. ed. Nova York: W. H. Freeman and Company, 2008.

Oliveira, G. S. et al. Molecular modeling of enzyme attachment on AFM probes. Journal of Molecular Graphics and Modelling, v. 45, p. 128-136, 2013.

PARK, S. et al. Free energy calculation from steered molecular dynamics simulations using Jarzynski's equality. J. Chem. Phys., v. 119, n. 6, p. 3559-3566, 2003.

PARK, S.; Schulten, K. Calculating potentials of mean force from steered molecular dynamics simulations. The Journal of Chemical Physics, v. 120, n. 13, p. 5946-5961, 01 abr. 2004. Parravicini, C. et al. Forced unbinding of GPR17 ligands from wild type and R255I mutant receptor models through a computational approach. BMC Structural Biology, v. 10, n. 1, p. 8, 16 mar. 2010.

Pearson, W. R. Rapid and sensitive sequence comparison with FASTP and FASTA. Methods Enzymol, v. 183, p. 63-98, 1990.

Searching protein sequence libraries: comparison of the sensitivity and selectivity of the Smith-Waterman and FASTA algorithms. Genomics, v. 11, p. 635-650, nov. 1991.

Pearson, W. R.; Lipman, D. J. Improved tools for biological sequence comparison. Proc Natl Acad Sci USA, v. 85, p. 2444-2448, abr. 1988.

Peitsch, M. C. Protein modeling by e-mail. Nat Biotech, v. 13, p. 658-660, 1995.

. About the use of protein models. Bioinformatics, v. 18, p. 934-938, jul. 2002.

Pharkya, P.; Nikolaev, E. V.; Maranas, C. D. Review of the BRENDA Database. Metab Eng, v. 5, p. 71-73, abr. 2003.

Pruitt, K. D.; TAtusova, T.; Maglott, D. R. NCBI reference sequences (RefSeq): a curated non-redundant sequence database of genomes, transcripts and proteins. Nucleic Acids Res, v. 35, p. D61-D65, jan. 2007.

QIAN, B. et al. High-resolution structure prediction and the crystallographic phase problem. Nature, v. 450, p. 259-264, nov. 2007.

Ramachandran, K. I.; Deepa, G.; Namboori, K. Computational chemistry and molecular modelling: principles and applications. 1. ed. Heidelberg: Springer, 2008.

RAPAPORT, D. C. The art of molecular dynamics simulation. 2. ed. Cambridge: Cambridge University Press, 2004.

RHodes, G. Crystallography made crystal clear: a guide for users of macromolecular models. 3. ed. San Diego: Elsevier, 2006.

ŠAli, A.; Blundell, T. L. Comparative protein modelling by satisfaction of spatial restraints. J Mol Biol, v. 234, p. 779-815, dez. 1993.

SÁNCHEZ, R.; ŠAli, A. Comparative protein structure modeling. In: Webster, D. M. (Ed.). Protein structure prediction: methods and protocols. Nova York: Kluwer, 2000. p. 97-130. 
Santos-Filho, O. A.; Alencastro, R. B. Modelagem de proteínas por homologia. Quím. Nova, v. 26, p. 1-14, mar. 2003.

Schomburg, I. et al. Enzyme data and metabolic information: BRENDA, a resource for research in biology, biochemistry, and medicine. Gene Function \& Disease, v. 1, p. 109-118, out. 2000 .

. BRENDA in 2013: integrated reactions, kinetic data, enzyme function data, improved disease classification: new options and contents in BRENDA. Nucleic Acids Res, v. 41, p. D764-D772, jan. 2013.

Schwede, T. et al. SWISS-MODEL: an automated protein homology-modeling server. Nucleic Acids Res, v. 31, p. 3381-3385, jul. 2003.

SEnN, H. M.; ThIEL, W. QM/MM methods for biomolecular systems. Angewandte Chemie (International ed. in English), v. 48, n. 7, p. 1198-1229, 2009.

$\mathrm{SHIH}$, A. Y. et al. Coarse grained protein-lipid model with application to lipoprotein particles. The Journal of Physical Chemistry, B, v. 110, n. 8, p. 3674-3684, 02 mar. 2006.

SINGH, S. et al. Identification and characterization of novel small-molecule inhibitors against hepatitis delta virus replication by using docking strategies. Hepatitis Monthly, v. 11, n. 10, p. 803-809, 01 out. 2011.

SirCAR, A. Methods for the homology modeling of antibody variable regions. Methods in Molecular Biology, Clifton, v. 857, p. 301-311, 2012.

Smith, C. A.; Rayment, I. Active site comparisons highlight structural similarities between myosin and other P-loop proteins. Biophys J, v. 70, p. 1590-1602, abr. 1996.

Sotomayor, M.; Schulten, K. Single-molecule experiments in vitro and in silico. Science, v. 316, n. 5828, p. 1144-1148, maio 2007.

Suhrer, S. J. et al. Effective techniques for protein structure mining. In: OrRY, A. J. W; Abagyan, R. (Ed.). Homology modeling: methods and protocols. 1. ed. Nova York: Springer, 2012. p. 33-54.

Sutter, E. et al. Scanning tunneling microscopy on epitaxial bilayer graphene on ruthenium (0001). Applied Physics Letters, v. 94, n. 13, p. 133101-1-133101-3, 30 mar. 2009.

TAmayo, J. et al. High-Q dynamic force microscopy in liquid and its application to living cells. Biophysical Journal, v. 81, n. 1, p. 526-537, jul. 2001.

TAPAszTó, L. et al. Tailoring the atomic structure of graphene nanoribbons by scanning tunnelling microscope lithography. Nature Nanotechnology, v. 3, n. 7, p. 397-401, jul. 2008.

Thompson, J. D.; Higgins, D. G.; Gibson, T. J. CLUSTAL W: improving the sensitivity of progressive multiple sequence alignment through sequence weighting, position-specific gap penalties and weight matrix choice. Nucleic Acids Res, v. 22, p. 4673-4680, nov. 1994.

Tress, M. et al. Assessment of predictions submitted for the CASP6 comparative modeling category. Proteins, v. 61, supl. 7, p. 27-45, 2005. 
Trotт, O.; Olson, A. J. Software news and update AutoDock Vina: improving the speed and accuracy of docking with a new scoring function, efficient optimization, and multithreading. Journal of Computational Chemistry, v. 31, n. 2, p. 455-461, 30 jan. 2010.

VAN der Kamp, M. W.; Mulholland, A. J. Combined quantum mechanics/molecular mechanics (QM/MM) methods in computational enzymology. Biochemistry, v. 52, p. 27082728, abr. 2013.

Van Gunsteren, W. F.; King, P. M.; Mark, A. E. Fundamentals of drug design from a biophysical viewpoint. Quarterly Reviews of Biophysics, v. 27, n. 4, p. 435-481, 1994.

Venclovas, C. Methods for sequence-structure alignment. In: Orry, A. J. W.; Abagyan, R. (Ed.). Homology modeling: methods and protocols. 1. ed. Nova York: Springer, 2012. p. 55-82.

Venselaar, H.; Krieger, E.; Vriend, G. Homology modeling. In: Gu, J.; Bourne, P. E. (Ed.). Structural bioinformatics. 2. ed. Hoboken: John Wiley \& Sons, 2009. p. 715-732.

VenselaAR, H. et al. Homology modelling and spectroscopy, a never-ending love story. Eur Biophys J, v. 39, p. 551-563, mar. 2010.

Voet, D.; Voet, J. G. Biochemistry. 4. ed. Kendallville: Wiley, 2011.

Vreven, T. et al. Combining quantum mechanics methods with molecular mechanics methods in ONIOM. Journal of Chemical Theory and Computation, v. 2, n. 3, p. 815-826, maio 2006.

Vyas, V. K. et al. Homology modeling a fast tool for drug discovery: current perspectives. Indian J Pharm Sci, v. 74, p. 1-17, jan. 2012.

Wooley, J. C.; Lin, H. S. Catalyzing inquiry at the interface of computing and biology. 1. ed. Washington, D.C.: The National Academies Press, 2005.

XIANG, Z. Advances in homology protein structure modeling. Curr Protein Pept Sci, v. 7, p. 217-27, jun. 2006.

Xu, Y.; Xu, D.; LIANG, J. Computational methods for protein structure prediction and modeling. 1. ed. Nova York: Springer, 2007. v. 2.

YUAN, M. et al. Computer-aided molecular modeling study on antibody recognition of small molecules: an immunoassay for triazine herbicides. Journal of Agricultural and Food Chemistry, v. 60, n. 42, p. 10486-10493, out. 2012.

ZHANG, D. et al. A novel antibody humanization method based on epitopes scanning and molecular dynamics simulation. PLoS ONE, v. 8, n. 11, p. 1-10, 21 nov. 2013.

ZHANG, Y. Progress and challenges in protein structure prediction. Curr Opin Struct Biol, v. 18, p. 342-348, jun. 2008.

Protein structure prediction: when is it useful? Curr Opin Struct Biol, v. 19, p. 145155, abr. 2009.

Zsoldos, Z. et al. eHiTS: an innovative approach to the docking and scoring function problems. Current Protein \& Peptide Science, v. 7, n. 5, p. 421-435, out. 2006. 